CHARACTERIZATION OF INCONEL 718: USING THE GLEEBLE AND VARESTRAINT TESTING METHODS TO DETERMINE THE WELDABILITY OF INCONEL 718

\author{
In Partial Fulfillment \\ of the Requirements for the Degree \\ Master of Science in Engineering with Specializations in Materials Engineering
}

Nathaniel Oscar Knock

Advisors: Dr. Daniel Walsh, Dr. Trevor Harding

November 2010 
(C) 2008

Nathaniel Oscar Knock

ALL RIGHTS RESERVED 
COMMITTEE MEMBERSHIP

TITLE:

Characterization of Inconel 718: Using Gleeble and Varestraint Testing Methods to Determine the Weldability of Inconel 718

AUTHOR:

Nathaniel Oscar Knock

DATE SUBMITTED:

November 2010

COMMITTEE CHAIR:

Daniel W. Walsh, Professor

COMMITTEE MEMBER:

Trevor Harding, Professor, Department Chair

COMMITTEE MEMBER: Blair London, Professor 


\section{Abstract \\ CHARACTERIZATION OF INCONEL 718: USING THE GLEEBLE AND VARESTRAINT TESTING METHODS TO DETERMINE THE WELDABILITY OF INCONEL 718}

Nickel based superalloys were developed to withstand the severe thermal and mechanical environment associated with rocket propulsion systems and jet engines. In many alloy systems the strength of a component rapidly deteriorates as the operating temperature increases. Nickel based superalloys, however, retain strength over a range of temperatures which includes the operating range for many propulsion systems. This improved performance is accomplished by a combination of solid-solution strengthening, precipitation strengthening and grain-boundary strengthening. Furthermore, super-alloy systems are designed for ease of fabrication, to include machining, welding and heat treating. Inconel 718 was developed to overcome problems with post-weld cracking that were common in precipitation hardened nickel based superalloys strengthened by $\gamma^{\prime}$. Inconel 718 is strengthened by $\gamma^{\prime \prime}$ and is less sensitive to cracking during post-weld thermal treatment. However, in some cases, compositional changes which improved the behavior of these alloys during stress relief actually led to greater difficulty during the joining process.

Many approaches have been used to determine the hot-cracking sensitivity of Inconel 718. Historically, two approaches have been particularly valuable because of their repeatability, their ability to compare different alloy systems and their verisimilitude to actual fabrication. These are the Gleeble hot-ductility test and the Variable-Restraint (Varestraint) weld test. Varestraint samples were prepared as per standard preparation techniques and tested longitudinally with a GTAW. At a predetermined location a strain was applied perpendicular to 
weld direction. The applied strain varied from $0.25 \%, 0.5 \%, 1.0 \%, 2.0 \%$, and $4.0 \%$. The Inconel 718 yielded a maximum crack length of $0.6 \mathrm{~mm}$ with a saturation strain of $2.0 \%$. Both the total crack length and the number of cracks did not have a saturation strain.

Gleeble samples were prepared from rod stock and tested with standard methodology to determine the characteristic temperatures: nil ductility, nil strength, and ductility recovery temperature of Inconel 718. The samples were tested at various pull temperatures on-heating until the nil strength temperature then tested on-cooling with the nil strength temperature acting as the peak temperature. The nil strength temperature was $2273^{\circ} \mathrm{F}$, nil ductility temperature was $2182^{\circ} \mathrm{F}$, and the ductility recovery temperature was $1925^{\circ} \mathrm{F}$.

Both the Varestraint and Gleeble results were compared with relevant literature to determine the weldability of the Inconel 718 . Four criteria were used to determine the weldability of Inconel 718 and in three of the four tests; the Inconel 718 had equal to or greater weldability than the compared materials. In the fourth test, the Inconel 718 demonstrated lower weldability than the compared alloy systems, however, Inconel 718 operates in different conditions specifically, the high temperature and pressure conditions mentioned above.

Key Terms: Inconel 718; Varestraint; Gleeble; nil strength temperature; nil ductility temperature; ductility recovery temperature; 


\section{Acknowledgements}

I want to start by thanking my family without who continually pushed me to be the best I could be. I would also like to thank my loving parents, Mel and Mary Kay, for their tireless financial and emotional support throughout all these years. I want to thank my advisors, Dr. Dan Walsh and Dr. Trevor Harding, who have supported this project from the beginning. Again, I extend many thanks to Pratt and Whitney Rocketdyne for their donation in support of my project. And of course, I want to thank all the friends, professors, and classmates, who have been there through the good and the bad over these wonderful past five years. 


\section{Contents}

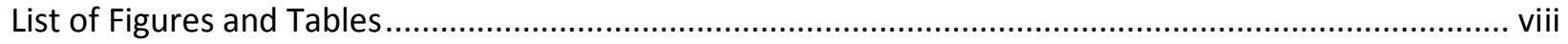

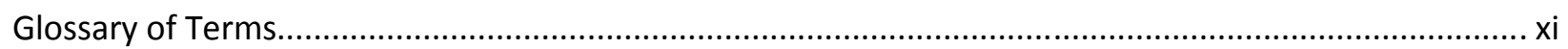

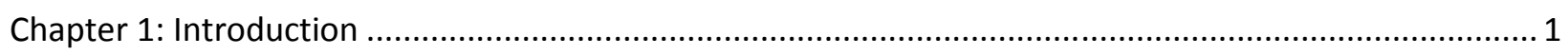

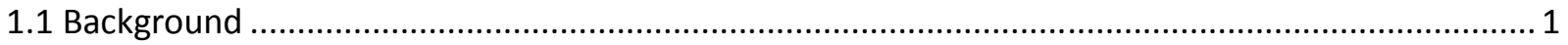

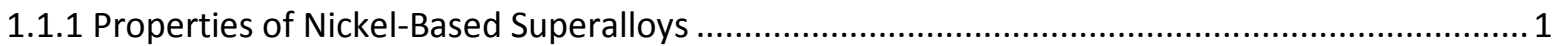

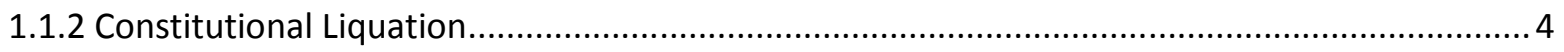

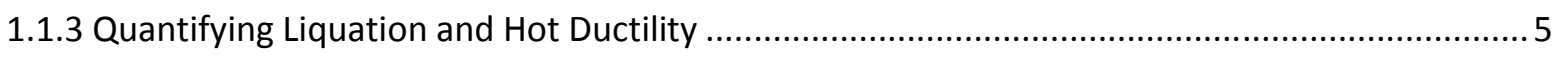

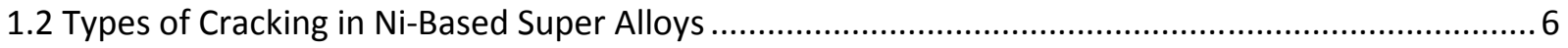

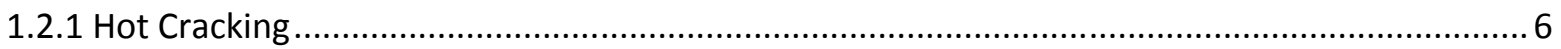

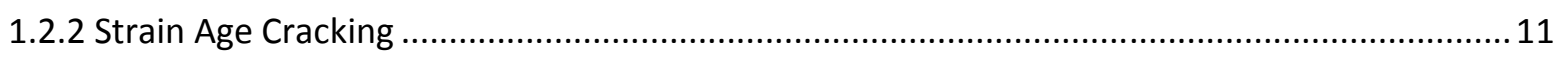

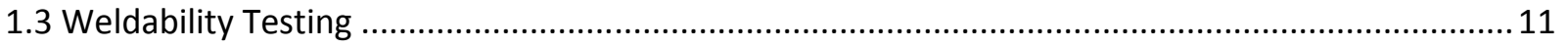

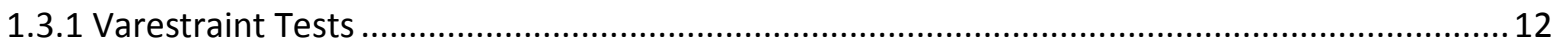

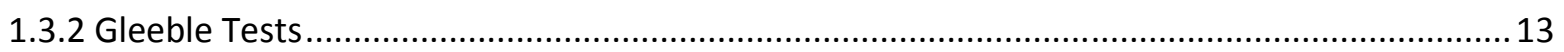

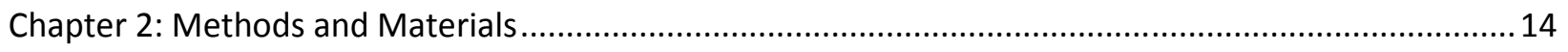

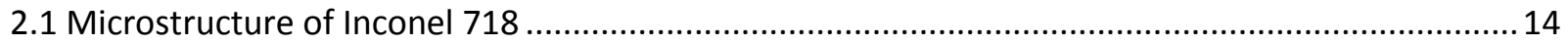

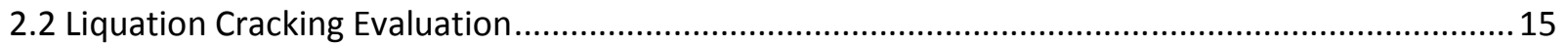

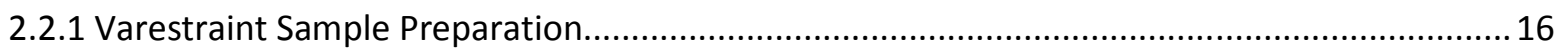

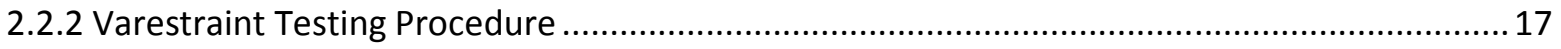

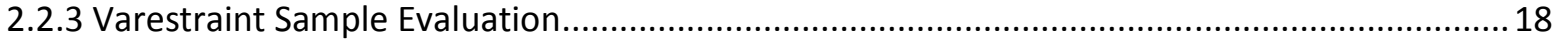

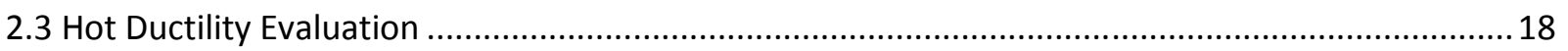

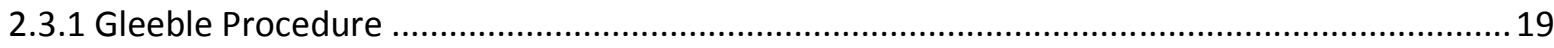

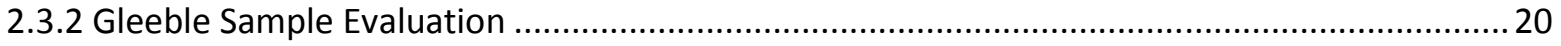

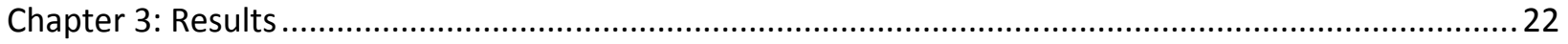

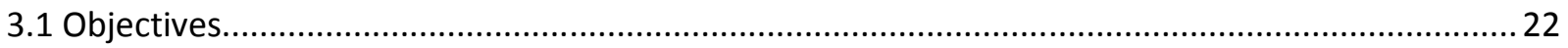

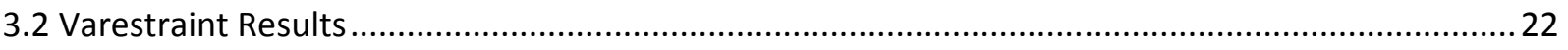

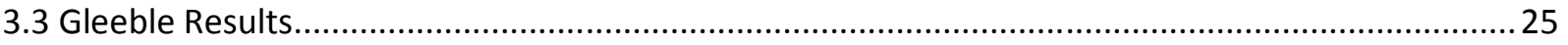

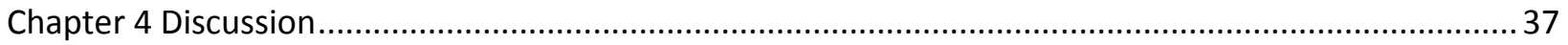

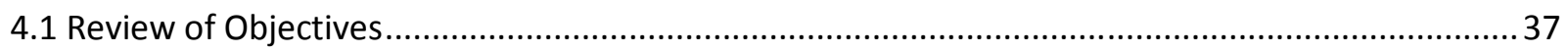


4.2 Comparison of Results with Relevant Literature

4.3 Comparison of Weldabilty with Relevant Literature …............................................................ 38

4.3.1 Classification of On-Heating and On-Cooling Curves - Nippes Criterion................................... 38

4.3.2 Rate of Ductility Recovery On-Cooling - Duvall Criterion....................................................... 40

4.3.3 Temperature Range Between the NST and the DRT - Williams Criterion ................................ 43

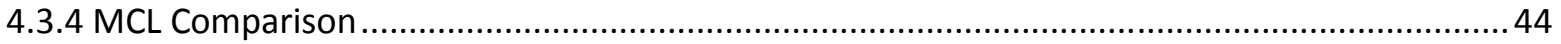

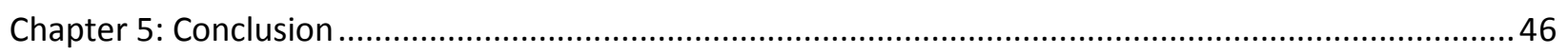

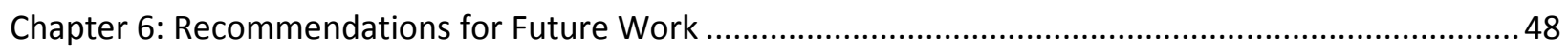

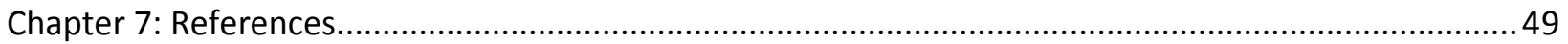




\section{List of Figures and Tables}

Table I: Chemical Composition of Inconel $718^{28}$

Figure 1: 1a (Left) shows the randomly distributed $y$ phase while $1 \mathrm{~b}$ (right) shows the ordered behavior of the $\gamma^{\prime}$ phase. Like the $\gamma^{\prime}$ phase, the $\gamma^{\prime \prime}$ follows an ordered structure.

Figure 2: Similar to the $\gamma^{\prime}$ phase, the $\gamma^{\prime \prime}$ phase has an ordered structure with Nb making up the corners and center. The BCT structure significantly increases the strength of the alloy at service temperatures.. 3 Figure 3: A typically binary phase diagram in which the AxBy precipitates can cause constitutional liquation. Alloy is evaluated at composition X1....

Figure 4: Hot cracking takes the form of solidification cracks in the fusion zone and liquation cracks in the heat affected zone.

Figure 5: Borland's Generalization Theory for hot crack formation is a four stage process. According to the theory, supersolidus cracks are most likely to form during Stage 3 and subsolidus cracks in Stage $4 .{ }^{17}$....

Figure 6: The Modified Crack Theory builds on the Generalized Theory proposed by Borland 30 years prior. This theory introduces the idea of sub-stages within the third stage. These sub-stages take into account crack initiation (3h) as well as propagation (3l).

Figure 7: Hydrogen can become trapped at triple-point grain boundaries (arrows) causing DCC with the application of small strains.

Figure 8: Brittle temperature range is frequently used as a way to quantify solidification cracking........ 12 Figure 9: Grain structure of tested samples demonstrated typical structure of Inconel including twinning (a) and precipitates pullout (dark spots).

Figure 10: Varestraint samples were manufactured to have similar length width and thicknesses and machined with gaps to allow insertion into Varestraint test apparatus.

Figure 11: Varestraint test device was used to characterize hot crack susceptibility in Inconel 718.

The device can recreate welds with a high degree of repeatability.

Figure 12: Varestraint test specimen were optically analyzed by measuring the perpendicular crack length (blue) and full crack length (red) of cracks that extend from the HAZ (a) to the base metal (b)....18 Figure 13: Gleeble samples were fabricated to specific dimensions in order to increase repeatability. Shaded sections of the sample were held within the Gleeble jaws.

Figure 14: Gleeble Test apparatus: Gleeble specimen are held within the load cells and heated according to predetermined program to measure NST, NDT, and DRT.

Figure 15: The total crack length was plotted against strain. The average sample had a threshold strain at $0.5 \%$ (orange) with no apparent saturation strain.

Figure 16: The number of cracks each sample experience also saw a threshold strain at $0.5 \%$ (orange) and like total crack length, no apparent saturation strain.

Figure 17: The maximum crack length was the most important value for determining weldability because of its saturation strain at $2 \%$ (red). $2 \%$ strain is estimated as the saturation strain as it appears to be the value where crack length does not increase. As expected, the MCL threshold strain was $0.5 \%$ (orange).

Figure 18: MCL (blue) sizes appears relatively constant when compared to the TCL (red) leading to conclusion that saturation strain is approached for the $\mathrm{MCL}$ at $2 \%$ strain. 
Figure 19: On-heating Gleeble results showed that the NDT occurred at roughly $2182^{\circ} \mathrm{F}$ as determined by the $5 \%$ area reduction. On-cooling Gleeble results show that the DRT is much lower than the NDT. The DRT is $1925^{\circ} \mathrm{F}$, about $200^{\circ} \mathrm{F}$ cooler than NDT.

Figure 20: Low on-heating temperatures $\left(1577^{\circ} \mathrm{F}\right)$ demonstrate the ductile behavior expected of the material as evident by the ductile fracture surface. The microvoid coalescence fracture surface is a sign of ductile failure.

Figure 21: As the on-heating temperature increases $\left(1987^{\circ} \mathrm{F}\right)$, the grains become more refined, before coarsening, and fracture becomes more brittle.

Figure 22: Further embrittlement and continued refinement as the on-heating pull temperature increases $\left(2073^{\circ} \mathrm{F}\right)$, but stays below the NDT.

Figure 23: Finally, as the pull temperature $\left(2188^{\circ} \mathrm{F}\right)$ passes the NDT the grains become coarse with a significant degree of intergranular brittle fracture.

Figure 24: Apparent precipitates coarsening and migration to grain boundaries are the primary reason Inconel 718 is able to retain its strength at elevated temperatures.

Figure 25: The lack of grain definition, when compared to figure 24, demonstrates an in abiltity to support its structure and the possible formation of a liquid phase as expected at the NST.

Figure 26: The on-cooling fracture surface showed evidence of non-defined grains as seen in the NST samples visually showing samples did not recover ductility until well below NDT.

Figure 27: As the on-cooling temperature decreased $\left(1930^{\circ} \mathrm{F}\right.$, left), it continued to show little evidence of brittle fracture leading to the conclusion that a persistent liquid phase was present around grain boundaries. This lack of ductile behavior is noticed when compared to more ductile samples evaluated at lower temperatures (right).

Figure 28: On-cooling samples did not show evidence of ductile fracture until the pull temperature fell well below the NDT. The sample seen here, $1870^{\circ} \mathrm{F}$, began to show evidence of microvoid coalescence finally showing evidence of ductility recovery.

Figure 29: On-cooling samples began showing similar fracture mechanisms to its on-heating equivalents after significant cooling $\left(1626^{\circ} \mathrm{F}\right)$.....

Figure 30: These curves are used as a method to classify weldability of a material. The on-heating curve $\mathrm{H} 1$ means the material may be weldable but must then compare on-cooling curves. The oncooling curve $\mathrm{C} 1$ and $\mathrm{C} 2$ mean the material is readily weldable. ${ }^{38}$

Figure 31: By comparing the curves seen here developed from Gleeble testing of the Inconel 718 sample with the curves outlined by the Nippes criterion, weldability can be determined. The onheating curve matches best to $\mathrm{H} 1$ while the on-cooling curve matches best with $\mathrm{C} 2$ leading to the conclusion that Inconel 718 is weldable.

Figure 32: Duvall tested four different alloys to determine the relationship between ductility recovery and weldability. He determined that the smaller the temperature range, the more readily weldable the material. According to his results, the Alloy 718 is the most weldable as it recovers its ductility in approximately $150^{\circ} \mathrm{F} .{ }^{40}$

Figure 33: When compared to the alloys in Figure 4, the Inconel is more weldable as it appears to recover its ductility in roughly $50^{\circ} \mathrm{F}$, a smaller temperature range than the smallest, Alloy $\mathrm{X}$ with ductility recover temperature of $200^{\circ} \mathrm{F}$. 
Figure 34: By comparing the MCL of various samples a comparative base can be developed for materials to prevent hot cracking. The shorter the $M C L$ developed at the saturation strain for a material, the less susceptible the material is to form hot cracks. The Inconel 718 sample had the shortest MCL making it the most weldable. 


\section{Glossary of Terms}

NDT - The nil ductility temperature is the temperature at which the material's ductility drops to zero. It is caused by the formation of a liquid between grains. The material is able to retain some strength due to capillary forces. In this study the NDT was calculated at 5\% area reduction based on the area reduction versus temperature curve.

NST - The nil strength temperature is the temperature where enough liquid has formed between grains to eliminate the capillary force found at the NDT. This study found the NST when the material was unable to support a $20 \mathrm{lb}$ load.

DRT - The ductility recovery temperature is the on-cooling temperature where the material regains sufficient ductility. It is a function of the peak temperature and usually is much lower than the NDT. Like the NDT, this study calculated the DRT at 5\% area reduction.

$\mathrm{HAZ}$ - The heat affected zone is the region just outside the weld pool that sees a change in microstructure brought about by the rapid heating brought on by the welding process. It is the region most affected by solidification cracks.

DDC - Ductility dip cracking is a solid state, intergranular cracking phenomenon that occurs during intermediate to high temperature processes, such as welding. These cracks occur after the alloy is subjected to small strains, due to a lack of ductility.

MCL - The maximum crack length is the measured value determined from the Varestraint test that best relates to a material's susceptibility to form hot cracks.

TCL - The total crack length is calculated by summing the length of each crack for a given sample. This value can be related to hot crack susceptibility when a saturation total crack length is available. 


\subsection{Background}

\section{Chapter 1: Introduction}

As World War II came to a close, scientists and researchers continued their development of jet turbine engines. These engines ran at much higher temperatures and performed in higher capacities than the propeller based engines of the day. These engines required metal alloys that could withstand the demanding conditions found within the new engines. Newly crafted "superalloys" were able to retain their strength even after continuous exposure to temperatures above $1200^{\circ} \mathrm{F}$. Nickel superalloys (referred to as Ni-based superalloys) are one of three major classes of superalloys.

\subsubsection{Properties of Nickel-Based Superalloys}

Ni-alloys are processed two ways; solid solution strengthened or precipitation strengthened. Solid solution strengthened alloys are primarily used in applications which require low to modest strength. The higher strength demanding applications require the precipitation strengthened alloys. The ability of the precipitation strengthened alloy to keep its strength at the higher temperatures can be explained by changes in microstructure caused by heat treatment along with a specific alloy composition.

In general, Ni-alloys contain a wide variety of alloying elements which dramatically change the properties of the base metal. The primary alloying elements range from $10-20 \% \mathrm{Cr}$, 5-10\% Co, up to $25 \% \mathrm{Mo}$, and up to $8 \% \mathrm{Ti}$ and Al. Secondary alloying elements can be added to change the corrosion resistance, creep properties, strength, and grain refinement behaviors of Ni-alloys. The alloying elements, themselves, are categorized as gamma phase formers, gamma prime phase formers, carbide formers, and grain boundary segregators (elements likely to segregate to grain boundaries). ${ }^{1}$ 
Gamma formers are elements found in Group V, VI, or VII and have similar atomic sizes to Ni. These elements include Co, Cr, and Mo. Gamma prime formers are Group III, IV, and V elements with atomic size difference larger than gamma formers. Gamma prime formers include $\mathrm{Al}$ and $\mathrm{Ti}$ in nickel-based super alloys. Carbide formers and grain boundary segregators have significantly larger differences in atomic size than the gamma forming elements. Primary alloying elements, including $\gamma$ and $\gamma^{\prime}$ formers, are the elements responsible for the high temperature strength of these alloys.

$\mathrm{Ni}$-alloys consist of a primary face-centered-cubic (FCC) austenitic matrix phase $(\gamma$ phase) with a variety of secondary phases. This primary phase usually contains a high percentage of solid solution elements such as Co, Cr, and Mo, the $\gamma$ formers, which are randomly distributed with the Ni atoms throughout the unit cell (Figure 1a). ${ }^{2}$ The phase responsible for the high strength of Ni-alloys is the $\mathrm{FCC}$ like, $\mathrm{Ni}_{3}(\mathrm{Al}, \mathrm{Ti})$ gamma prime phase $\left(\gamma^{\prime}\right)$. Other secondary phases include niobium or vanadium based precipitation phases $\left(\gamma^{\prime \prime}\right.$, to be discussed later) and various carbide phases.

In the $\gamma^{\prime}$ phase, the $\mathrm{Ni}$ atoms lie on the face centers with the $\mathrm{Ti}$ and $\mathrm{Al}$ atoms residing in the corners of the unit cell (Figure 1b). ${ }^{3}$ Since $\gamma^{\prime}$ has a similar lattice parameter and it is chemically compatible with $\gamma$, $\gamma^{\prime}$ can precipitate homogeneously throughout the $\gamma$ matrix. Furthermore, like most precipitation strengthened materials, the $\gamma^{\prime}$ phase impedes
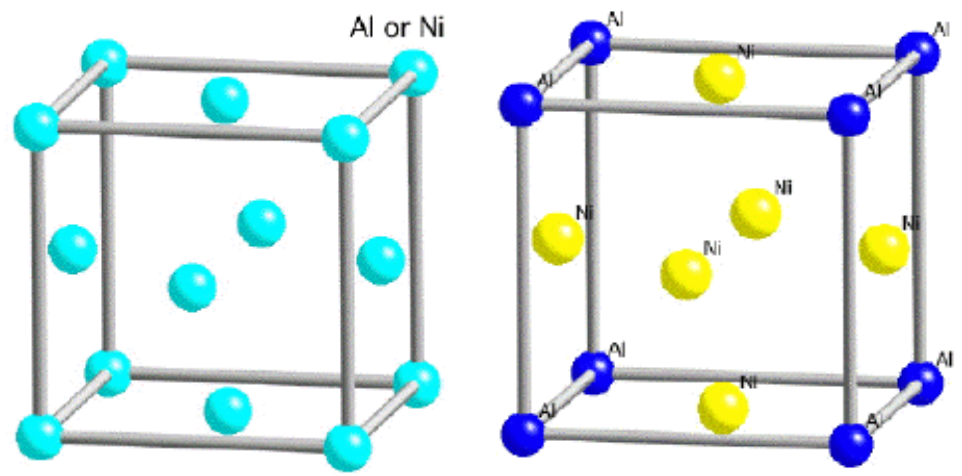
dislocation movement,

Figure 1: 1a (Left) shows the randomly distributed $\gamma$ phase while $1 \mathrm{~b}$ (right) shows the ordered behavior of the $\gamma^{\prime}$ phase. Like the $\gamma^{\prime}$ phase, the $\gamma^{\prime \prime}$ follows an ordered structure. ${ }^{2}$ 
increasing the strength of the alloy. At higher temperatures, the presence of the $\gamma^{\prime}$ phase causes the formation of anitphase boundaries preventing dislocation movement. As a result, the dislocations become locked, causing the noticeable increase in strength.

Carbides are another secondary phase which can increase the strength of Ni-alloys at high temperatures. Carbides usually come in three different varieties which include $\mathrm{MC}, \mathrm{M}_{23} \mathrm{C}_{6}$, and $\mathrm{M}_{6} \mathrm{C}$, where a variety of metals can make up the metallic portion of the carbide. $\mathrm{M}_{23} \mathrm{C}_{6}$ and $\mathrm{M}_{6} \mathrm{C}$ carbides are usually $\mathrm{Cr}$ based but the $\mathrm{MC}$ carbides can comprise of $\mathrm{Cr}, \mathrm{Ni}, \mathrm{Co}, \mathrm{Fe}, \mathrm{Mo}$, or W. Carbide phases usually strengthen the Ni-alloy in three distinct ways. The first is that carbides, when formed on grain boundaries as precipitates, can prevent grain boundary sliding and allow stress relaxation. Unfortunately, when improperly formed, such as during welding treatments, the carbides can form as grain boundary films leading to grain boundary embrittlement. ${ }^{4}$ The second property is that fine carbides can be precipitated throughout the $\gamma$ matrix, adding considerable strength to the matrix. ${ }^{5}$ Lastly, the carbides are able to "tie up" elements that would cause instability at high temperatures, preventing these elements from migrating to and weakening grain boundaries.

When increased strength is needed at lower temperatures Ni-alloys can be precipitation strengthened with the $\gamma^{\prime \prime}$ phase (Figure 2). This phase, similar to the $\gamma^{\prime}$, is formed with a significant addition of $\mathrm{Nb}$ atoms to the alloy; in Inconel 718 , the $\mathrm{Nb}$ content can reach up to $5.1 \%{ }^{3}$ The $\mathrm{Ni}_{3} \mathrm{Nb}$ forms a body-centered-tetragonal unit cell with similar order as seen in $\gamma^{\prime}$ arrangement.

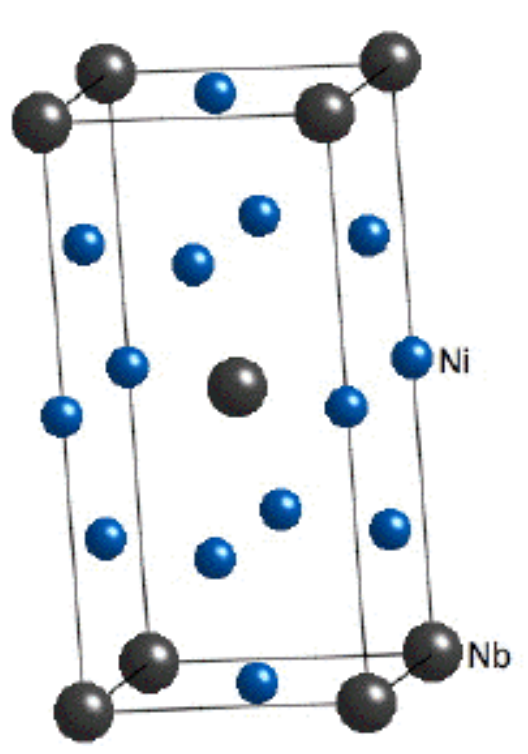

Figure 2: Similar to the $\gamma^{\prime}$ phase, the $\gamma^{\prime \prime}$ phase has an ordered structure with $\mathrm{Nb}$ making up the corners and center. The BCT structure significantly increases the strength of the alloy at service temperatures. ${ }^{2}$ 
Unfortunately, this increased strength comes with problems as the presence of $\mathrm{Nb}$ increases the susceptibility of the alloy to form liquation cracks during the welding process. ${ }^{6}$

\subsubsection{Constitutional Liquation}

The theory of constitutional liquation was developed after researchers discovered that at temperatures below the solidus temperature of a given alloy, liquid phases were still present. ${ }^{7}$ The theory states that liquation occurs when at least two different solid phases react to form a liquid phase where only a single solid phase should be present. By utilizing a eutectic phase diagram for a binary alloy system, constitutional liquation can be explained (Figure 3). For a given alloy with the composition of $\mathrm{X}_{1}$, when heated to $\mathrm{T}_{1}$, the microstructure would consist of an $\alpha$ solid phase with $A_{x} B_{y}$ precipitates. When heated at a rate near thermodynamic equilibrium, the $A_{x} B_{y}$ precipitates would dissolve at the solvus temperature, $T_{\text {solvus }}$, and the $\alpha$-phase would start to melt at the solidus temperature, $\mathrm{T}_{\text {solidus. }}$ However, during rapid heating procedures, such as welding, the $A_{x} B_{y}$ precipitates have not had time to melt and some survive past the point of liquid formation past $\mathrm{T}_{\text {solidus }}$

This effectively changes the composition of the alloy as a significant portion of precipitates remained and did not form into liquid. ${ }^{8}$

When rapidly cooled to $\mathrm{T}_{\text {solidus }}$, the liquid is unable to solidify, due to its

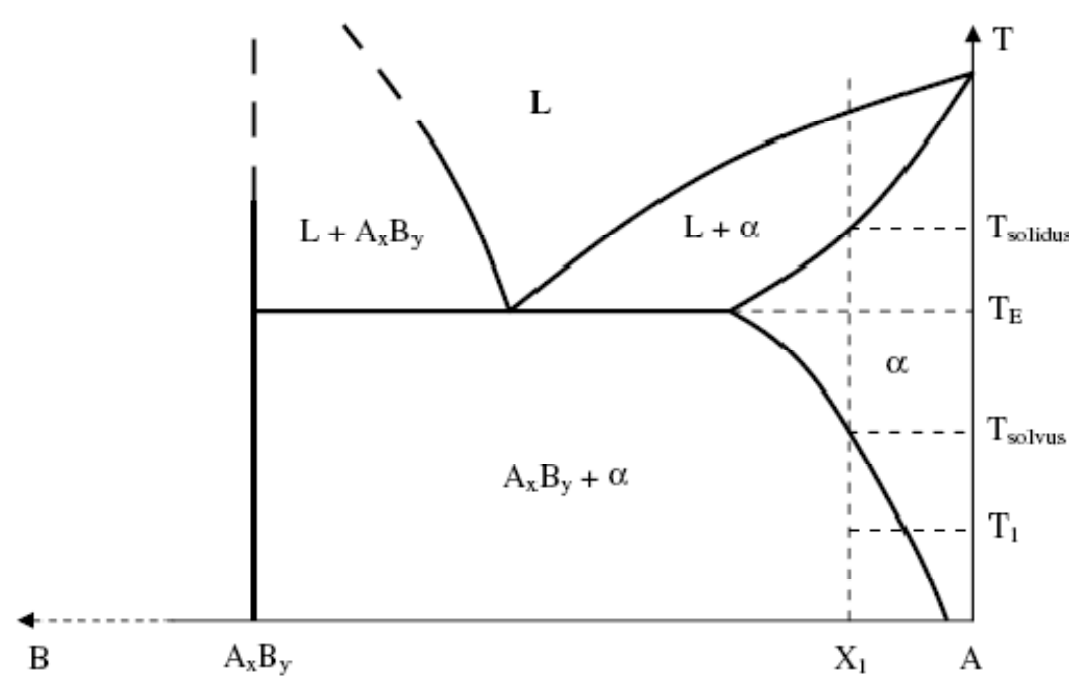

Figure 3: A typically binary phase diagram in which the $A_{x} B_{y}$ precipitates can cause constitutional liquation. Alloy is evaluated at composition $\mathrm{X}_{1}$. 
changed composition, creating a B rich liquid between $\alpha$-phase grains. These $\alpha$-phase grains are a result of the primary formation during initial processing of the Ni alloy. The non-dissolved liquid phase that was unable to diffuse out grows rapidly adding stress to the $\alpha$-matrix.

In the case of Inconel 718 , the $\mathrm{Nb}$ behaves as the $\mathrm{B}$ on the above phase diagram. Since the $\mathrm{Nb}$ do not diffuse into the $\gamma$ matrix fast enough, they tend to grow larger when cooled. During subsequent treatments, the $\gamma^{\prime \prime}$ precipitates loose $\mathrm{Nb}$ to grain boundaries, significantly weakening the alloy. ${ }^{9}$ If the alloy is then subjected to strains which exceed the available ductility, cracking occurs. These cracks are commonly referred to as ductility dip cracks. ${ }^{10}$

\subsubsection{Quantifying Liquation and Hot Ductility}

In order to determine the range of cracking within a material, several quantifiable parameters were develed. ${ }^{11}$ These parameters are the nil ductility temperature (NDT) the nil strength temperature (NST) and the ductility recovery temperature (DRT). Both the NDT and NST are considered 'on-heating' properties, properties that occur during welding, while the DRT is considered an on-cooling property.

The NDT is the temperature at which the ductility of the alloy drops to zero. The NDT is

defined as the temperature at which fracture occurs without the presence of plastic deformation. ${ }^{12}$ The NDT is characterized by the presence of a thin liquid film separating grain boundaries. At the NDT, the alloy can still demonstrate some strength due to capillary forces between grain boundaries, but the presence of liquid at the grain boundaries cause the ductility to remain low.

The NST is the temperature at which the strength of the alloy essentially drops to zero. As the alloy is heated from the NDT, the liquid film, separating the grain boundaries, slowly increases in thickness. As the film thickens, the strength decreases due to a reduction in the 
capillary forces holding the grains together. Eventually, the liquid layer thickens to the point at which minimal capillarity exists. ${ }^{13}$

Lastly, the DRT is the temperature, on-cooling, where the material regains detectable ductility; usually a percent area reduction above $5 \% .{ }^{14}$ This temperature is usually lower than the NDT due to the constitutional liquation phenomenon. As mentioned earlier, during nonequilibrium heating and cooling, liquid phases are present where only solid phases are expected. Since this liquid phase persists longer than predicted by the phase diagram, the nucleated grains remain separated by the liquid film, preventing any ductility recovery.

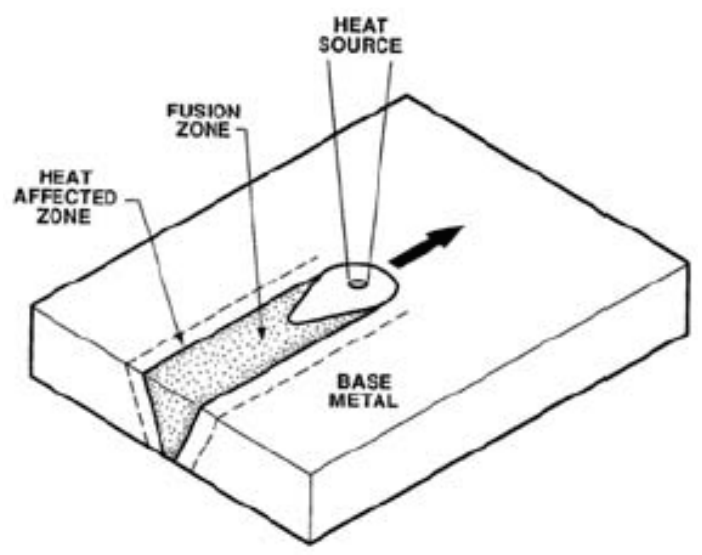

Figure 4: Hot cracking takes the form of solidification cracks in the fusion zone and liquation cracks in the heat affected zone. ${ }^{16}$

\subsection{Types of Cracking in Ni-Based Super Alloys}

\subsubsection{Hot Cracking}

Hot cracking is a term that refers to cracking that generally occurs during nonequilibrium heating such as welding or brazing treatments. Hot cracking can occur above the solidus temperature where it is known as supersolidus cracking or below the solidus temperature where it is classified as subsolidus cracking. ${ }^{15}$ Subsolidus cracking is a solid state cracking phenomenon that occurs between grains, referred to as ductility dip cracking.

Supersolidus cracking occurs during solidification and is caused by low melting temperature constituents, such as niobium, and stresses within the weld. ${ }^{16}$ These stresses are usually caused by solidification shrinkage or external loading. Unlike subsolidus cracking, 
supersolidus cracking occurs in the presence of solid and liquid phases generally with liquid films found on grain boundaries. Supersolidus cracks can occur in two locations: within the fusion zone where it is referred to as solidification cracking or within the heat affected zone (HAZ) where it is known as liquation cracking (Figure 4).

Two studies have examined the structure of the metal during cooling and tried to relate this to crack initiation and propagation. The first is the Generalized Theory of Hot Cracking as proposed by Borland. ${ }^{17}$ This theory, developed in 1960, outlined four key stages during solidification and defined these stages by the amount of solid and liquid phases present (Figure $5)$.

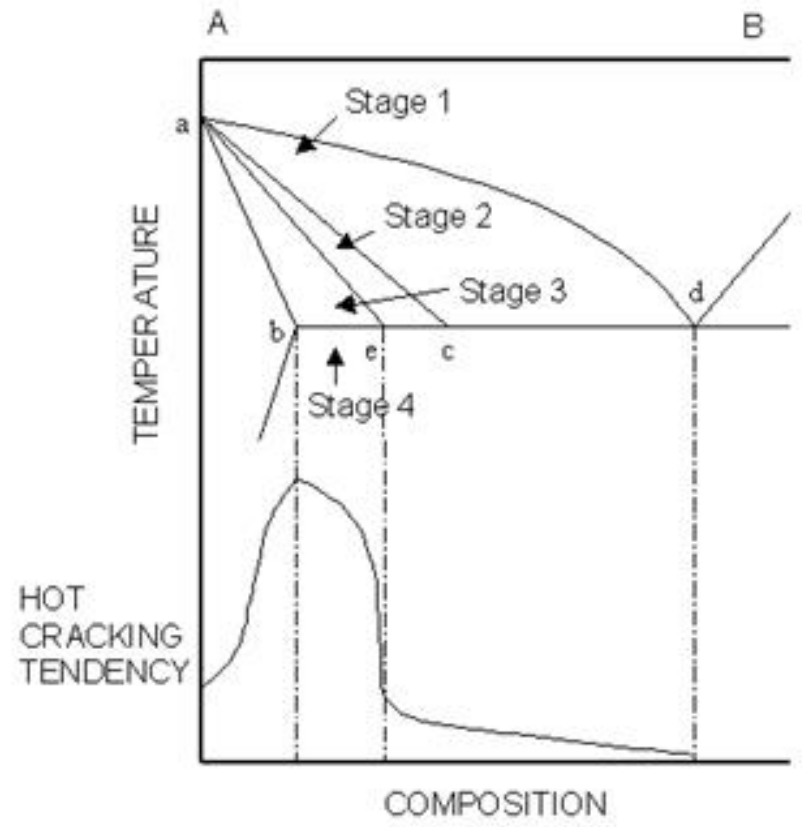

Figure 5: Borland's Generalization Theory for hot crack formation is a four stage process. According to the theory, supersolidus cracks are most likely to form during Stage 3 and subsolidus cracks in Stage $4 .{ }^{17}$

During Stage 1, the liquid phase is continuous with well dispersed solid phases initiating growth. As cooling continues into Stage 2, both the solid and liquid phases form an intertwined, continuous structure. One of the key components of this stage is the sufficient amount of liquid able to fill any cracks that form in the solid phase. Cooling continues into Stage 3 and a 


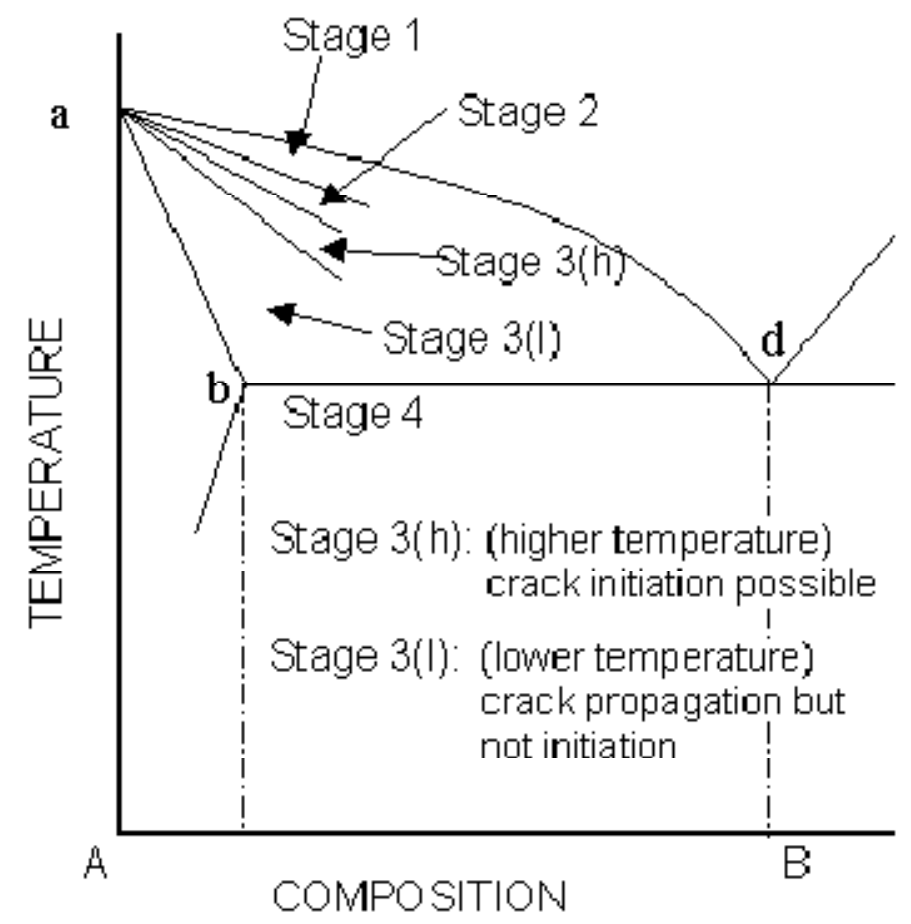

Figure 6: The Modified Crack Theory builds on the Generalized Theory proposed by Borland. This theory introduces the idea of sub-stages within the third stage. These sub-stages take into account crack initiation (3h) as well as propagation (3l). ${ }^{18}$

significant decrease in liquid is noticed. Due to the severely reduce liquid, cracks that form are unable to be refilled. It is this stage where the supersolidus cracks form. Finally Stage 4 is signified by the absence of liquid, the material has solidified. It is this stage that leads to the formation of subsolidus cracks.

Another theory, as proposed by Matsuda in the 1990's, suggested separating Stage 3 into two sub stages; Stage 3(h) where cracks initiate, and Stage 3(l) where cracks propagate (Figure 6). ${ }^{18}$ This Modified Crack Theory further tries to identify the mechanisms involved with solidification cracking. Both of these theories work to better understand the mechanisms the lead to the formation of hot cracks. 


\subsubsection{Subsolidus Cracking: Ductility Dip Cracking}

Ductility dip cracking (DDC) is an intergranular cracking phenomenon that occurs during intermediate to high temperature processes, such as welding, in many alloy systems, including Ni-based superalloys. Its name comes from the idea that cracking occurs, after the alloy is subjected to small strains, due to a lack of ductility. DDCs can be considered an effect of the nil ductility temperature of Ni-alloys. DDCs have the potential to become surface cracks which are unacceptable due to the environments in-which Ni-alloys are typically used. ${ }^{19}$

These cracks commonly form in restrained welds and are thought to be caused by a variety of factors. The primary cause of DDC is likely hydrogen embrittlement. It has been traditionally thought that hydrogen cracking is of little concern in austenitic metals due to their high solubility and low diffusivity of hydrogen. However, one theory suggests that the diffusing hydrogen can become 'trapped' at inhomogeneities such as triple-point grain boundaries. ${ }^{20}$ Upon the application of a small strain, the hydrogen is rapidly released into grain boundaries, decreasing grain boundary cohesion, and leading to intergranular fracture (Figure 7).

Other factors that can cause DDC include grain boundary sliding, secondary phase $(\gamma ")$ precipitation, and a lack of grain boundary migration (creep). ${ }^{10,21}$ Other studies suggest that carbide forming elements, such as $\mathrm{Nb}$ and $\mathrm{Ti}$, may dominate in the formation of DDC. ${ }^{22}$ The carbides are thought to precipitate along grain boundaries during welding, increasing the strength but greatly decreasing the ductility.

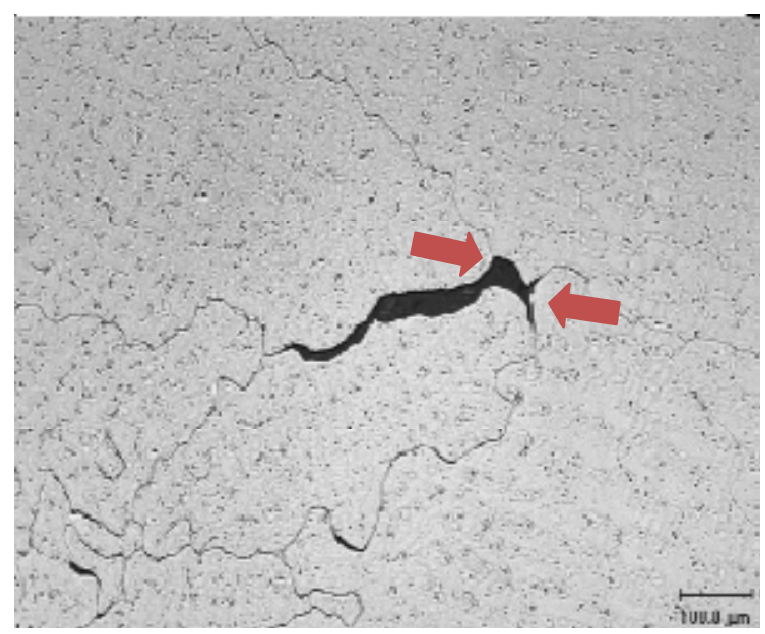

Figure 7: This Ni-based alloy demonstrates DDC after high temperature service. Hydrogen can become trapped at triple-point grain boundaries (arrows) causing DDC with the application of small strains. ${ }^{20}$ 


\subsubsection{Supersolidus Cracking: Solidification Cracking}

Solidification cracking, known as hot cracking or hot tearing, occurs during welding, casting, or hot working temperatures near the melting temperature of the alloy. As mentioned earlier, solidification cracks usually occur within the fusion zone of a weld. Since solidification cracking is not a steady state phenomenon, they generally form during cooling just after welding. As the material cools, internal stresses within the metal place strain on the solidifying weld pool. Just as in DDC, cracking occurs because the weld metal is unable to support strain. Unlike DDC, solidification cracks can only occur during the solidification of the weldment.

There are two important factors that increase a metal's susceptibility to form solidifaction cracks: impurity concentration and internal strains. As with most materials, a high impurity concentration will increase the Ni-alloy's susceptibility to form solidification cracks. Likewise, high internal strains, usually remaining from production, will increase the crack susceptibility.

\subsubsection{Supersolidus Cracking: Liquation Cracking}

Liquation cracking is one of the most significant problems high performance Ni-alloys experience during welding. As mentioned earlier, it is caused by the presence of liquid films found around grain boundaries during cooling. These films are unable to accommodate the internal strains produced during production or the induced strains caused during weld cooling. ${ }^{14}$ Though the specific mechanisms for liquation cracking are unknown, the necessary components for crack formation are known. In order for liquation cracking to occur, the simultaneous presence of a susceptible microstructure and a critical level of grain restraint are required. 


\subsubsection{Strain Age Cracking}

Strain age cracking occurs when the $\gamma^{\prime}$ or $\gamma^{\prime \prime}$ forming elements are heated to solution annealing temperatures $\left(1100^{\circ} \mathrm{F}-1800^{\circ} \mathrm{F}\right.$ for Ni-alloys $)$ during postfabrication processes. The precipitated $\gamma^{\prime}$ and $\gamma^{\prime \prime}$ form solid solutions that pin grains, causing an increase in tensile stresses on the $\gamma$ matrix and a decrease in ductility. When the material experiences small strains, the already high internal tensile stresses cause cracking. ${ }^{23}$ This cracking is not limited to the weld metal or the HAZ, as in solidification and DDC, but can occur in unaffected base metal. ${ }^{24}$ In order to prevent strain age cracking from occurring, significant stress relaxation must occur prior to service through annealing. Unfortunately, for many welded components, the size and shape of the components prevent any relaxation procedures from occurring. Since many welded parts are unable to experience post-welding heat treatments, weldability tests have been developed to determine the weldability of different alloys.

\subsection{Weldability Testing}

Weldability is the capacity of a material to be welded, under imposed conditions, into a specific, suitably designed structure and to perform satisfactorily in the intended application. ${ }^{25}$ Weldability tests are usually research rather than production tests. Each test evaluates a specific weldability problem. Tests are usually used in the development of the alloy rather than during production. Since service condition testing is expensive and usually impossible, standardized tests and testing methods have been developed. The tests utilize base line conditions to create minimally allowed response, such as crack formation, for comparison purposes. Simple geometric shapes and configurations are used to create base line comparisons. The tests provide quantitative data to compare either different metals or similar metals in different heating or 
welding conditions. Weldability tests are unable to determine acceptance limits such as the yield strength of a welded material. The weldability tests are used to determine the susceptibility of the base material to crack under given conditions.

\subsubsection{Varestraint Tests}

Varestraint (variable restraint) tests are used to determine the susceptibility of an alloy to form solidification cracks during welding. The test uses a controlled, rapidly applied bending strain to produce cracking during actual welding of the alloy. By varying the amount of strain, a threshold

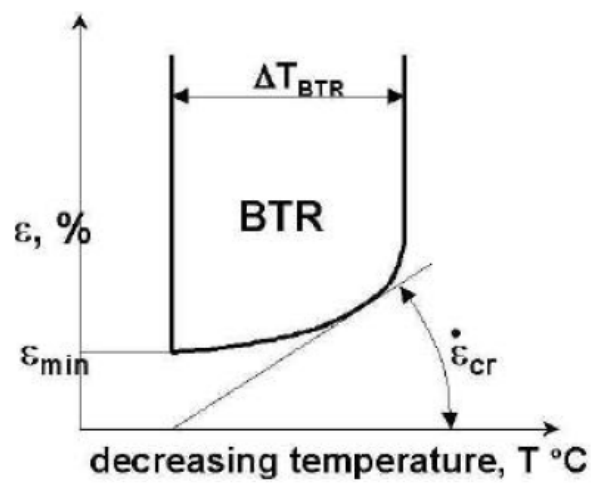

Figure 8: Brittle temperature range is frequently used as a way to quantify solidification cracking.

strain (the strain at which cracks form) and a saturation strain (the strain at which crack properties are strain independent) can be determined. After testing, the total and maximum cracking lengths are calculated. These crack lengths, along with the threshold and saturation strain are essential in determining the weldability of an alloy. ${ }^{26}$

By evaluating the maximum crack length, it is possible to determine the temperature range, during solidification, over which cracking will occur, better known as the brittleness temperature range (BTR). The BTR is important when determining the weldability because the larger this range, the more susceptible a material is to solidification cracking. While the BTR is the major factor in determining crack susceptibility, it is important to remember that the strain is responsible for crack creation. Therefore, by plotting the strain on a strain vs. temperature plot, the BTR $\left(\Delta \mathrm{T}_{\mathrm{BTR}}\right)$ can be determined (Figure 8$) .{ }^{27}$ It should be noted that as temperature decreases the strain required for cracking increases. 


\subsubsection{Gleeble Tests}

Gleeble tests are used to predict the bulk behavior of materials. The Gleeble is able to produce different regions, such as the HAZ and fusion zones, in large volumes of microstructure. ${ }^{19}$ During testing, small tensile samples are fractured at specified temperatures during the on-heating or on-cooling process. Many different variables are evaluated including heating and cooling rates, peak temperatures, hold times, and pull force. By varying these parameters, many results can be achieved including NDT and NST temperatures, crack susceptibility, and tensile behavior. Crack susceptibility testing, such as strain age crack susceptibility, is of primary concern in this study. The controlled heating rate test (CHRT), is an effective way to study the strain age cracking behavior of Ni-Alloys. ${ }^{16}$ 


\section{Chapter 2: Methods and Materials}

\subsection{Microstructure of Inconel 718}

The composition of Inconel 718 can vary but generally falls within certain compositional limits outlined in Table $\mathrm{I}^{28}$

Table I: Chemical Composition of Inconel $718^{28}$

\begin{tabular}{|l|c|c|c|c|c|c|c|c|c|c|c|}
\hline Alloying Element & $\mathrm{Ni}$ & $\mathrm{Cr}$ & $\mathrm{Nb}$ & $\mathrm{Mo}$ & $\mathrm{Ti}$ & $\mathrm{Al}$ & $\mathrm{Co}$ & $\mathrm{C}$ & $\mathrm{Mn}$ & $\mathrm{Si}$ & $\mathrm{Cu}$ \\
\hline Max (wt. \%) & - & 21.00 & 5.50 & 3.30 & 1.15 & 0.80 & 1.00 & 0.08 & 0.35 & 0.35 & 0.30 \\
\hline Min (wt. \%) & 50.00 & 17.00 & 4.75 & 2.80 & 0.65 & 0.20 & - & - & - & - & - \\
\hline
\end{tabular}

The tested Inconel 718 was donated by Rocketdyne and the composition and heat treatments are considered proprietary. The significant alloying element of Inconel 718, compared to other nickel-based superalloys, is the $4.75-5.50 \% \mathrm{Nb}$. The $\mathrm{Nb}$ is included to precipitation strengthen the alloy with the $\gamma^{\prime \prime}$ phase. To determine the structure of the Inconel 718 used in this experiment, one of the Varestraint test samples was sectioned and metallographically prepared. Using standard metallographic techniques the sample was polished and etched $\left(0.95 \mathrm{HCl}\right.$, and $\left.0.05 \mathrm{H}_{2} \mathrm{O}_{2}\right)$ to expose the microstucture (Figure 9). The grain structure was then analyzed to ensure test samples match known Inconel 718 grain structure. ${ }^{29}$ 


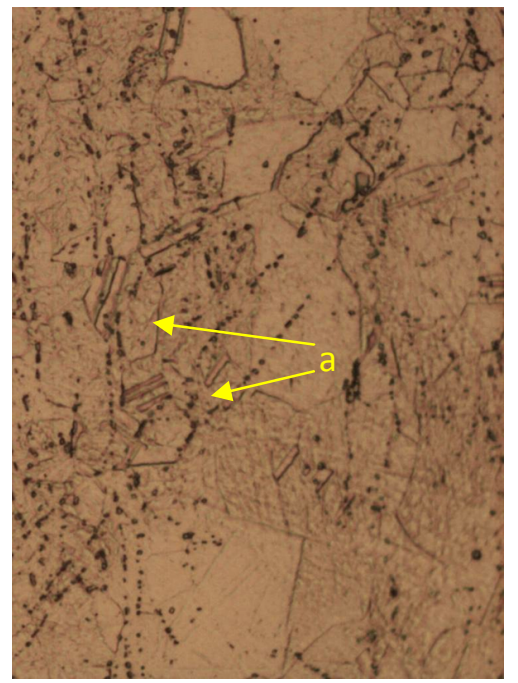

Imples demonstrated typical structure of

d precipitates pullout (dark spots) expected

\subsection{Liquation Cracking Evaluation}

In order to determine the weldabilty of Inconel 718 , tests were conducted to determine the material's response to various welding conditions. The Varestraint (variable restraint) weldability test yields information on the material's response to welding. ${ }^{30}$ This test simulates the effects welding has on the microstructure of the alloy by performing a repeatable weld and applying a consistent bending strain on each sample.

Developed in 1965, the Varestraint test is designed to evaluate solidification cracking in the HAZ of the weld ${ }^{31}$. The test has been used for a variety of different materials due to its ability to provide quantitative parameters in weld analysis. While other solidification crack tests exist, it is the quantitative results of the Varestraint test that cause it to be the most effective.

The test's efficacy originates from six criteria: ${ }^{32}$

1. Ability to show correlation between testing and service conditions.

2. Reproducibility of results by removal of human element in welds.

3. Ability to respond to small changes in test variability. 
4. Ability to demonstrate several weld variables.

5. Economic preparation of test specimen.

6. Applicability to all welding processes.

The purpose of utilizing this test is to define the weld characteristics of Inconel 718 to allow comparison with other alloys to determine weldability.

\subsubsection{Varestraint Sample Preparation}

Varestraint testing requires the fabrication of unique test samples. The specific dimensions of the sample are important as sample size can dictate the response of an alloy during welding. Thicker samples will not only diffuse heat differently, but will also cause changes in weld penetration depth and weld pool shape. ${ }^{33}$ These differences can be problematic as weld pool shape and flow can be used as a quick way to determine the consistency of welds. In order to ensure a similar response, the sample's length, width, and thickness $(5.35 \times 1.00 \times 0.125$ in $)$ were measured prior to testing. The samples were machined with slots on either end to fix the sample to the testing apparatus (Figure 10).

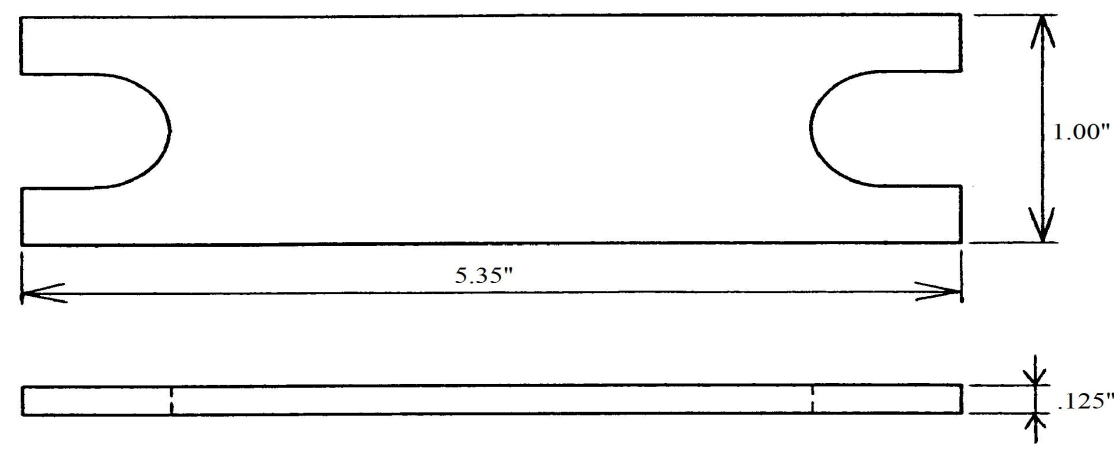

Figure 10: Varestraint samples were manufactured to have similar length, width, and thicknesses and machined with slost to allow insertion into Varestraint test apparatus. 


\subsubsection{Varestraint Testing Procedure}

Varestraint testing was

conducted on a Moving Torch,

Varestraint Hot Cracking Test

Device Model LT1100, Serial 9001, supplied by Materials Applications

Inc. The equipment consisted of an automated welding torch and a pneumatic straining assembly

(Figure 11). Prior to testing, each sample was measured and cleaned with ethanol to ensure uniformity

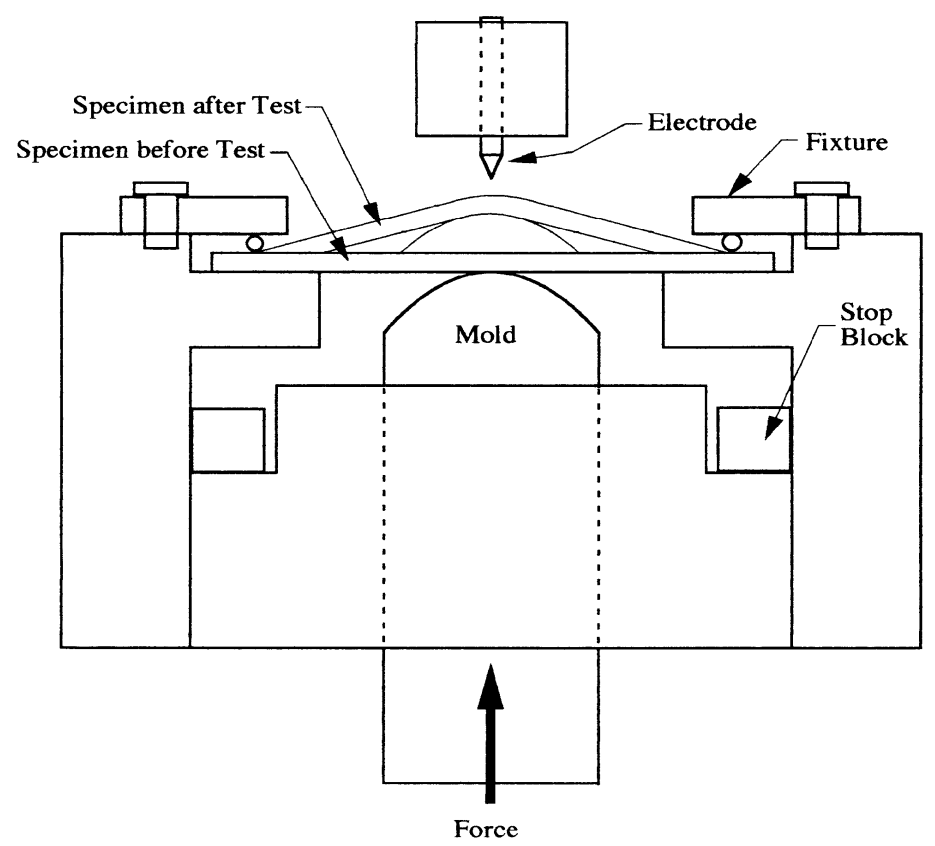

Figure 11: Varestraint test applies various amounts of strain to different samples. These strains are applied perpendicular to the weld in order to produce liquation cracks.

between samples. The test was conducted with a longitudinal weld allowing for the evaluation of the fusion zone and HAZ cracking. Each sample was subjected to one weld pass, using GTAW techniques, at approximately $10 \mathrm{~V}, 98 \mathrm{~A}$, and a welding speed of $5 \mathrm{in} \cdot \mathrm{min}^{-1}$, typical of Varestraint testing. ${ }^{25}$

A bending strain was applied producing cracking in the fusion zones and HAZ depending on applied strain. The strain applied is determined by the radius of the die block that is forced into the specimen. The relationship that governed the amount of applied strain was:

$$
\text { strain } \cong \frac{t}{2 r}
$$

Equation 1

Where $t$ is the sample thickness and $r$ is the die block radius. The applied strain levels were 0.5, 1, 2 and $4 \%$ for 0.125 " thickness. Three specimens were tested at each strain level. 


\subsubsection{Varestraint Sample Evaluation}

The Varestraint test applies a solidifying weld and a rapidly applied strain to a test sample. The rapid strain works to essentially freeze the weld pool and its thermal field at the time of the applied strain. This freezing of the thermal field allows for easy analysis of the weld thermal gradient. Maximum crack length, total crack length, and total number of cracks were measured using an optical microscope at $40 x$ (Figure 12). The surface was cleaned to remove surface oxide films to allow easier examination. Measured crack parameters were developed, then compared to the applied strain to determine weldability.

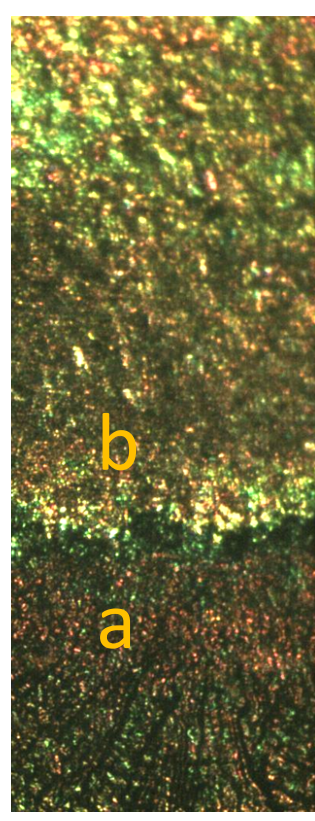

Ily analyzed by and full crack length e base metal (b).

\subsection{Hot Ductility Evaluation}

In order to determine the liquation crack susceptibility of a material, several properties of the material must be measured through the use of hot ductility testing. The nil-strength and nilductility temperatures are thermo-mechanical properties of materials that can be determined through examination of the weld HAZ. One method for evaluating weld HAZ is through Gleeble experimentation. 
The Gleeble, developed in the late 1940s, was originally designed to study the heat affected zone of arc welds. ${ }^{34}$ Eventually, a hydraulic servo was incorporated giving researchers the ability to examine the microstructures of materials in a repeatable fashion. The Gleeble soon became an industry standard as it could be utilized as a predictive system, eliminating the need for expensive product testing and process adjustments.

The Gleeble was used to determine the weldability of Inconel 718 by evaluating the properties of the weld HAZ to predict the formation of liquation cracks during welding.

\subsubsection{Gleeble Procedure}

Ductility dip crack testing was conducted on the Gleeble HAZ® 1000 thermo-mechanical weld simulator built by Dynamic Systems, Inc. Cylindrical rods, 5.00 in long and 0.25 in diameter were prepared by spot welding two thermocouple wires at the lengthwise center of each

\section{"}

tability. Shaded

sample (Figure 13).

The thermocouple wire was a platinum-platinum/rhodium wire and was used to monitor the temperature of the sample. The position of the spot weld must be at the center of the sample to ensure the maximum sample temperature is measured.

The first test conducted was the nil-strength temperature test. Each sample was placed into the Gleeble jaws and subjected to a nominal loading of $20 \mathrm{lb}$ tension (Figure 14). 


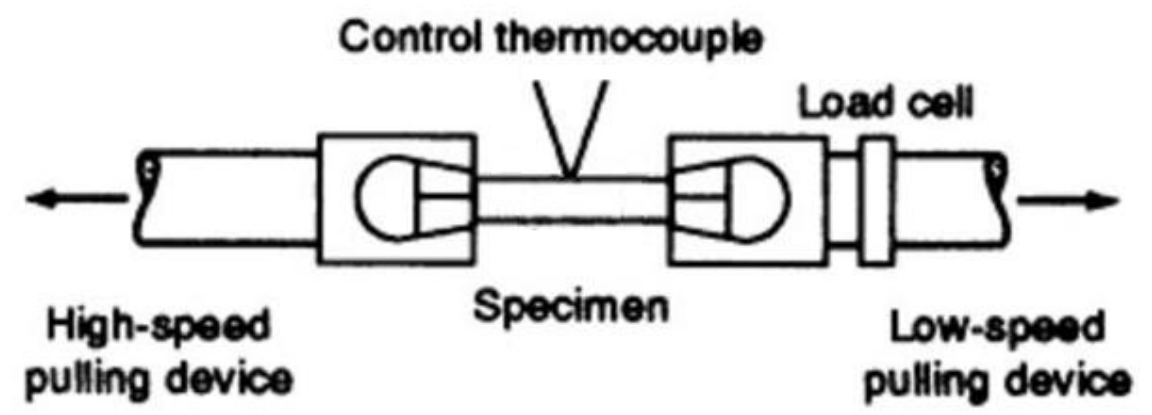

Figure 14: Gleeble Test apparatus: Gleeble specimen are held between the load cells and heated according to predetermined program to measure NST, NDT, and DRT. ${ }^{14}$

The samples were tested in a twice-evacuated chamber, back filled with argon gas to ensure an oxygen free environment. The samples were rapidly heated $\left(100^{\circ} \mathrm{F} \cdot \mathrm{s}^{-1}\right)$ until approximately $200^{\circ} \mathrm{F}$ below the nominal melting temperature of $2400^{\circ} \mathrm{F}$ for Inconel 718 . At this point, the heating rate was reduced to $\left(10^{\circ} \mathrm{F} \cdot \mathrm{s}^{-1}\right)$ and the sample was heated until the nominal loading caused fracture. The temperature at which the nominal loading caused fracture was recorded as the nil-strength temperature. The test was repeated three times.

The next test conducted was the nil-ductility test. These tests were conducted with a maximum temperature starting just below the nil strength temperature and reduced by $200^{\circ} \mathrm{F}$ after each failure. A similar testing setup was used as in the nil-strength test, however, when the maximum temperature was reached, the jaws of the Gleeble were stroked until sample failure. The maximum load and the fracture diameters were measured and recorded for each sample.

\subsubsection{Gleeble Sample Evaluation}

Gleeble testing produced two fracture surfaces for each test. Each fracture sample diameter was measured using a digital caliper as well as profilometer to ensure accuracy. The samples were then analyzed using the SEM to evaluate the fracture surface. After SEM analysis, 
the fracture surfaces were compared to determine the effects of the weld simulation on the microstructure of the Inconel 718 samples. 


\section{Chapter 3: Results}

\subsection{Objectives}

The objectives of this study are three fold:

1. Determine the threshold strain, saturation strain, and maximum crack length using Varestraint testing.

2. Use the Gleeble to measure the nil strength temperature, nil ductility temperature, and ductility recovery temperature.

3. Determine the weldabilty of Inconel 718 by relating Varestraint and Gleeble results with relevant literature.

\subsection{Varestraint Results}

Varestraint tests were performed on three samples at $0.25,0.5,1,2$, and $4 \%$ to determine the threshold and saturation strain for the Inconel 718 sample. After evaluating the samples as described in the Materials and Methods section, the total crack length (TCL) in mm, total number of cracks, and maximum crack lengths (MCL) in mm were averaged for each strain. The total number of cracks was plotted against the applied strain (Figure 15).

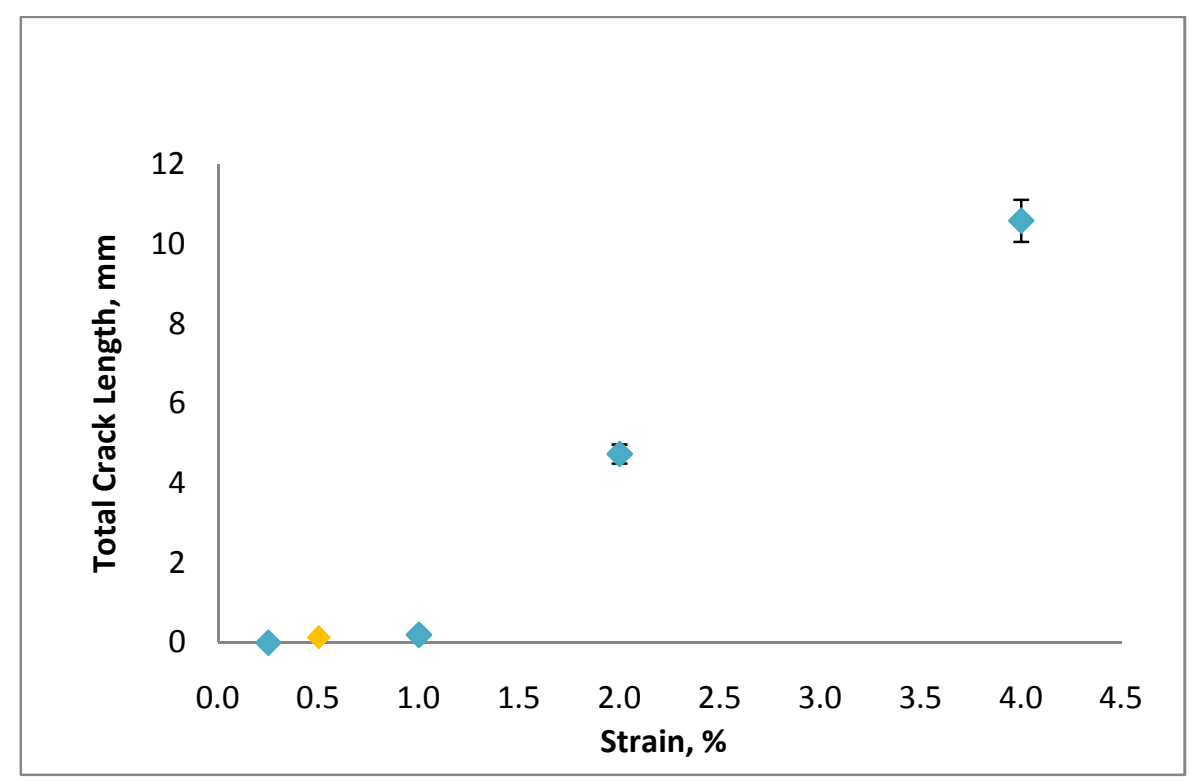

Figure 15: The total crack length was plotted against strain. The average sample had a threshold strain of $0.5 \%$ (yellow) with no apparent saturation strain. 
From the graph, it was possible to determine the threshold strain, the strain where cracking is initiated, and the saturation strain, the strain where crack length or number remains relatively constant. For the TCL, the threshold strain was $0.5 \%$ as its defined as the tested strain where cracking first appears. There was no apparent saturation strain. Inconel 718 will initiate cracking at low strain but total crack length will continue to increase with greater strain within the range of strains investigated here.

The next relevant information determined from the Varestraint test was the number of cracks each sample produced at the various strains (Figure 16).

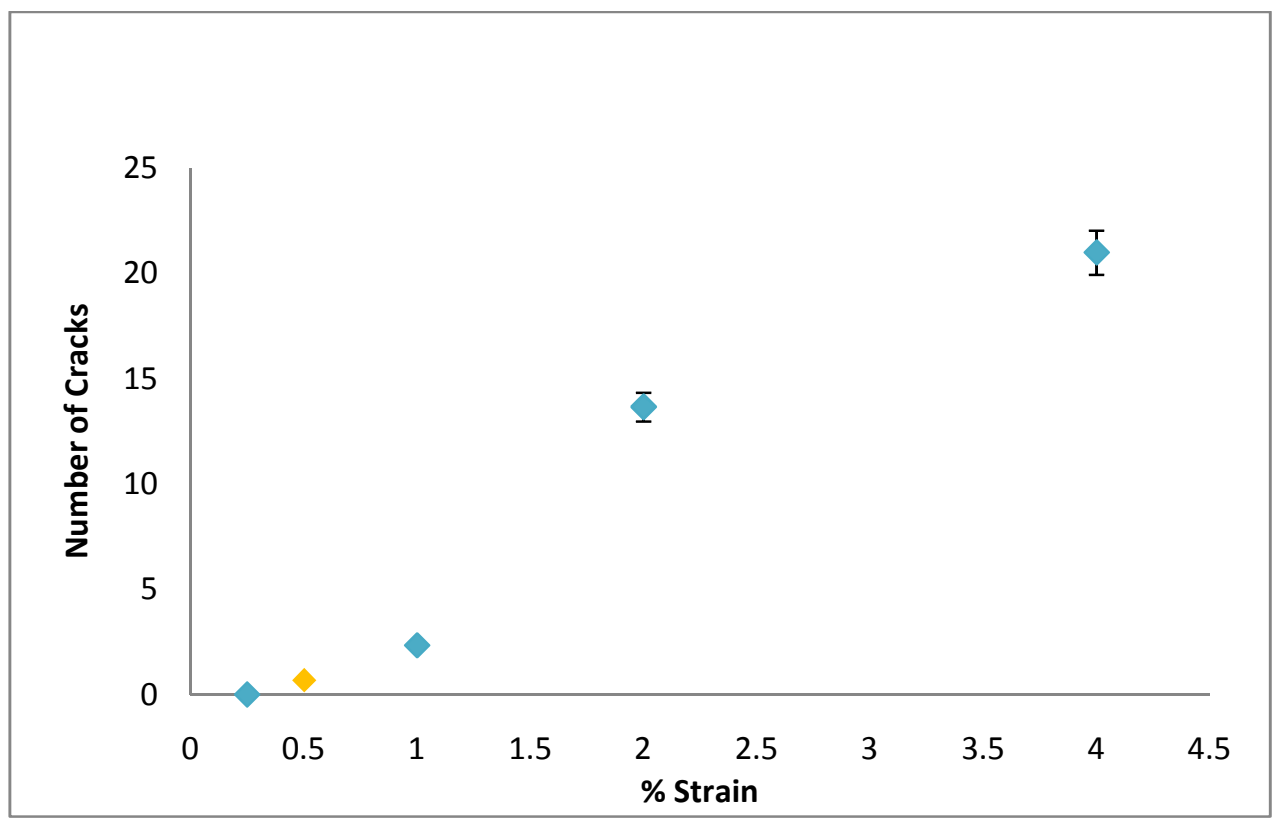

Figure 16: The number of cracks each sample experience also saw a threshold strain at $0.5 \%$ (yellow) and like total crack length, no apparent saturation strain.

Like the TCL, $0.5 \%$ strain was the first tested strain at which cracks appeared and the number continued to increase up to $4 \%$. The threshold strain was $0.5 \%$ with no apparent saturation strain. Lastly, the MCL was plotted against strain as in similar fashion to TCL and number of cracks (Figure 17). Like the other endpoints, the MCL had a threshold strain at $0.5 \%$ 
but unlike the other samples, a saturation strain may be evident between 2 and $4 \%$ but this conclusion cannot be determined from the tested data.

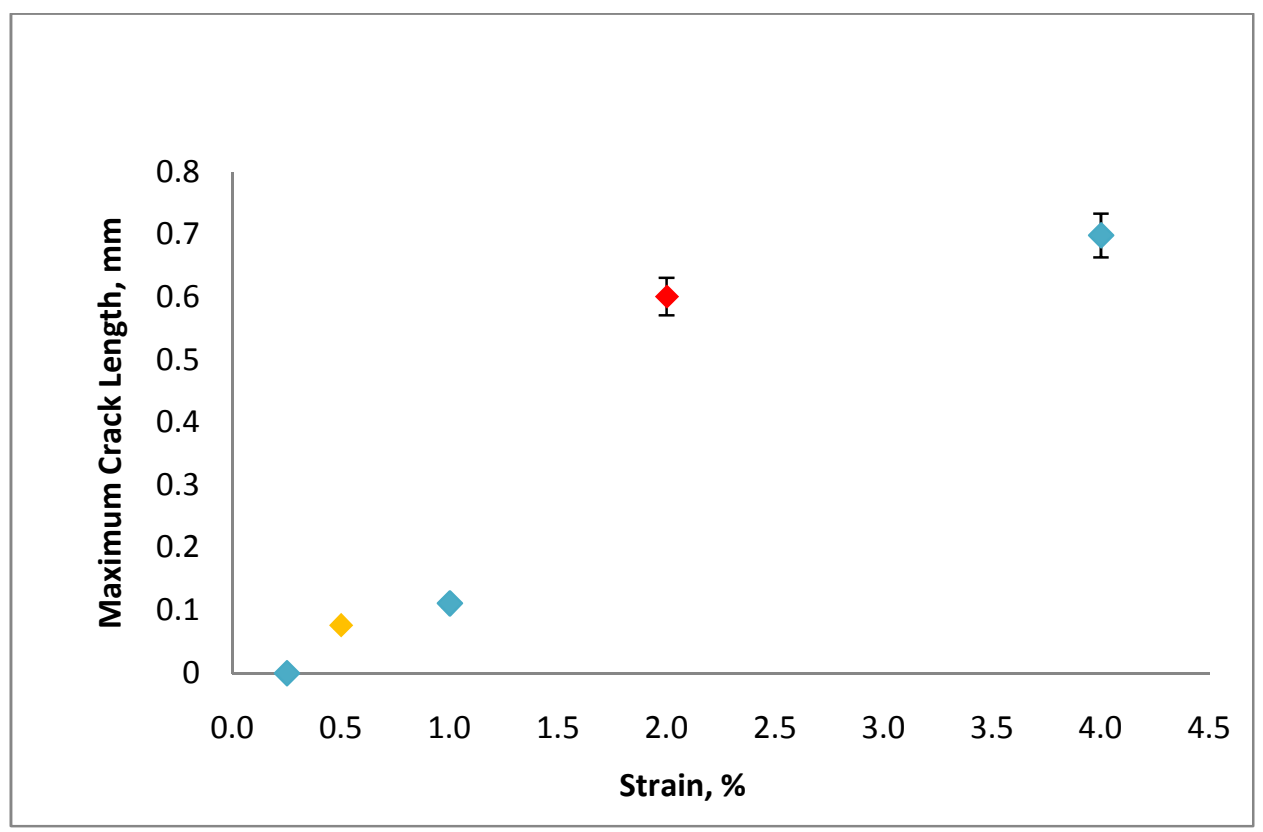

Figure 17: The maximum crack length was the most important value for determining weldability because of its saturation strain at $2 \%$ (red). $2 \%$ strain is estimated as the saturation strain as it appears to be the value where crack length approaches consistent length independent of strain. As expected, the MCL threshold strain was $0.5 \%$ (yellow).

Like the number of cracks and the TCL, the MCL saw the same threshold strain of $0.5 \%$, however, unlike the other two end points, the MCL may approach a saturation value at $2 \%$ strain. This result can be seen when comparing the crack lengths of the TCL and MCL at $2 \%$ and $4 \%$ strain (Figure 18). 


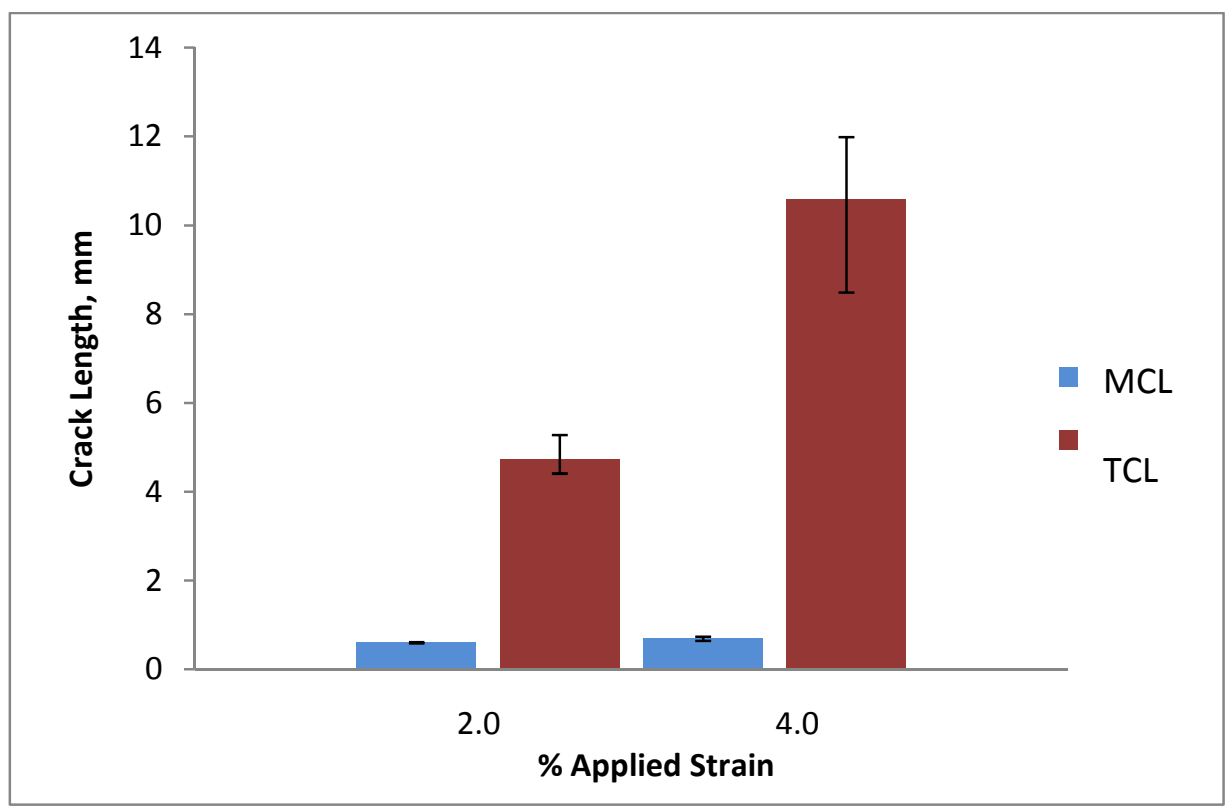

Figure 18: $\mathrm{MCL}$ (blue) sizes appears relatively constant when compared to the TCL (red) leading to conclusion that saturation strain is approached for the MCL at $2 \%$ strain.

As noticed in the above figure, as the applied strain is increased the maximum crack length remains relatively constant while the total crack length greatly increases. As the strain is applied, the material releases the applied strain energy by creating new interfaces in the form of crack surfaces. The larger strains do not increase crack surface by increasing individual crack lengths but rather by creating new cracks. This leads to an increase in the TCL while keeping the MCL relatively constant.

\subsection{Gleeble Results}

The goal of the Gleeble tests was to measure the nil strength temperature, nil ductility temperature, and the ductility recovery temperature. Using these temperatures, the nil-ductility region, brittle temperature range, and the crack susceptibility region were then calculated. These 
values are frequently used as methods for interpreting hot ductility testing results for HAZ cracking assessment. In order to determine the various temperatures for evaluation, the ductility was measured by determining the percent area reduction at each temperature. These values were then plotted against temperature for the on-heating and the on-cooling tests (Figure 19).

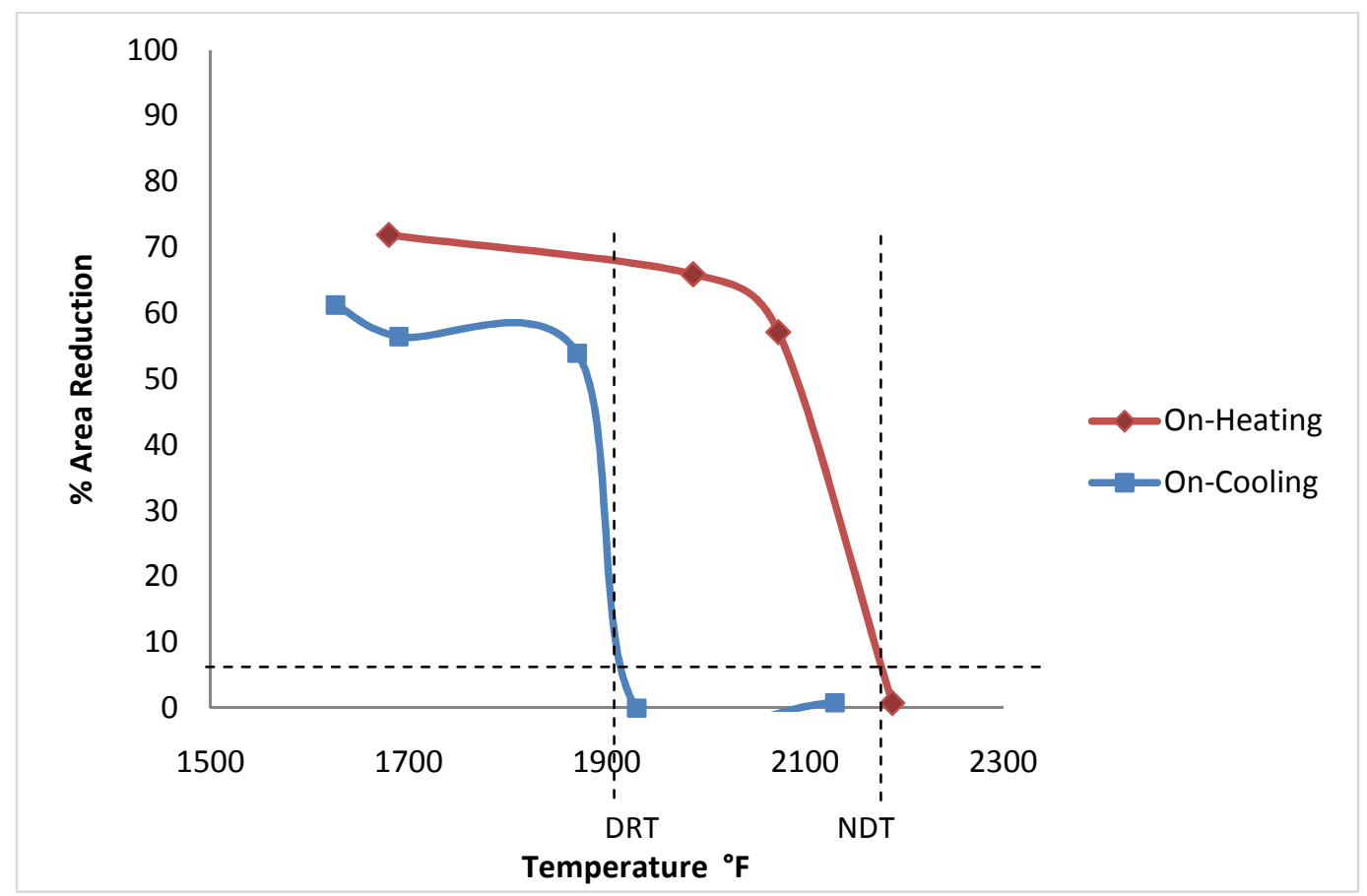

Figure 19: On-heating Gleeble results showed that the NDT occurred at roughly $2182^{\circ} \mathrm{F}$ as determined by the $5 \%$ area reduction. On-cooling Gleeble results show that the DRT is $1925^{\circ} \mathrm{F}$, about $200^{\circ} \mathrm{F}$ cooler than NDT.

The NST was measured by heating the material to its nominal melting temperature and subjecting the sample to a nominal load of $20 \mathrm{lbs}$. This yielded a NST of $2250^{\circ} \mathrm{F}$. This value was then used as the peak temperature for the on-cooling tests. The NDT $\left(2182^{\circ} \mathrm{F}\right)$ and DRT $\left(1925^{\circ} \mathrm{F}\right)$ were determined by fitting a curve to the graphs and calculating the temperature at $5 \%$ area reduction. One noted trend was the temperature range at which the material regained significant ductility. The material was able to recover approximately $60 \%$ of its ductility in a temperature range of approximately $100^{\circ} \mathrm{F}$. 
The fracture surfaces of the Gleeble samples were then analyzed using a scanning electron microscope (SEM). Using the SEM, the grain structures of the NST, NDT, and DRT were compared. At low pull temperatures the expected fracture surface would show evidence of microvoid coalescence because the material should not have lost any ductility that is brought on by changes in microstructure or accumulation of liquid between grains (Figure 20).

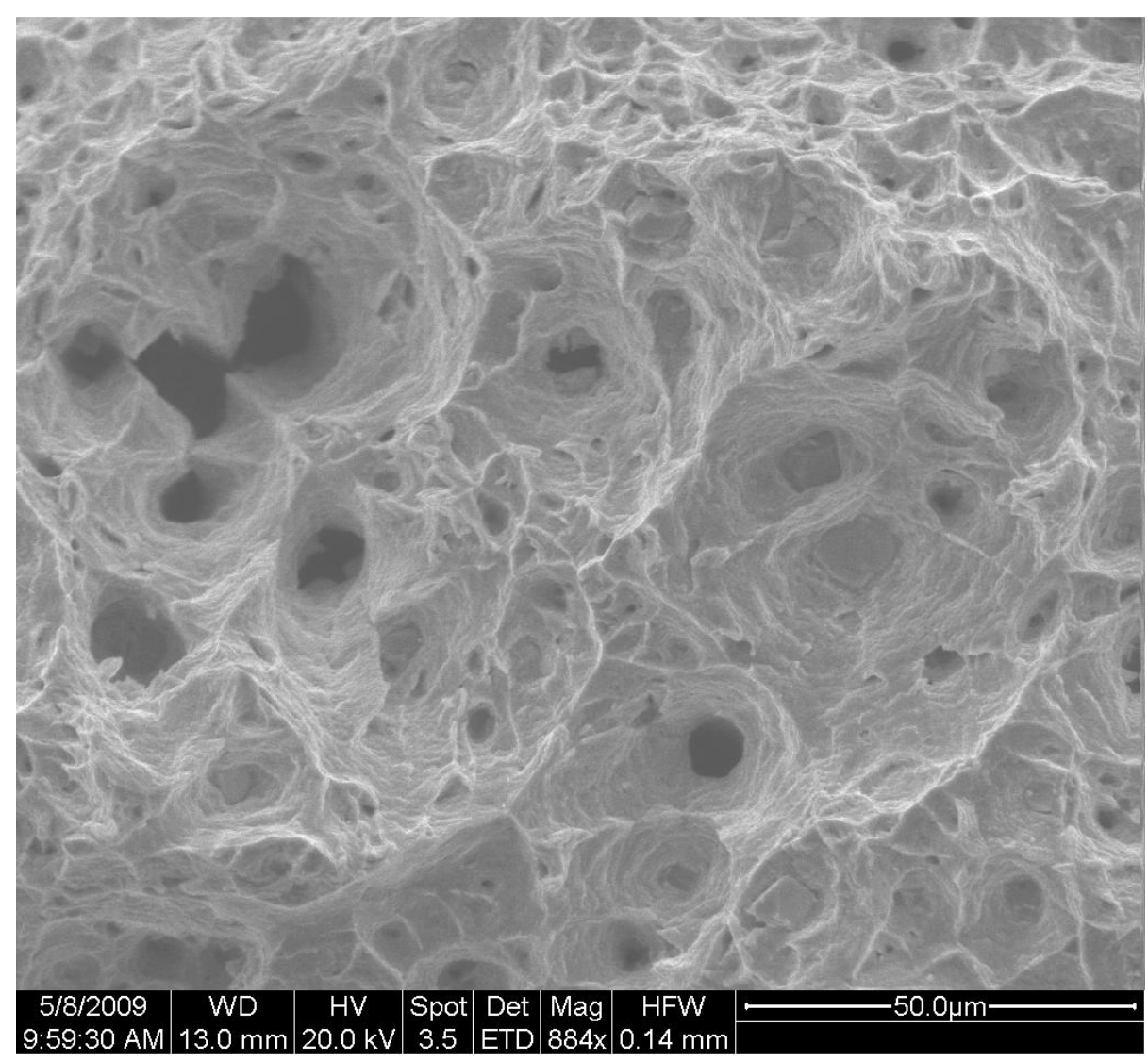

Figure 20: Low on-heating temperatures $\left(1680^{\circ} \mathrm{F}\right)$ demonstrate the ductile behavior expected of the material as evident by the ductile fracture surface (\%AR of $71.90 \%$ ). The microvoid coalescence fracture surface is a sign of ductile failure.

As expected, Figure 20 shows the microvoid coalescence leading to the conclusion that the material is ductile enough to demonstrate the ductile failure mechanisms that are involved with plastic deformation.

As the pull temperature increases, an expected trend would be for the grains to become refined before eventually coarsening at temperatures near the NST. This grain refinement is a 
common trend in the welded and weld simulated structures and is caused by recrystallization. The recrystallization is driven by stored strain energy from the original processing and usually occurs at $40 \%$ to $50 \%$ the melting temperature. This refined structure, as compared to the base metal grain size from Chapter 2, is seen in the Gleeble samples heated past the recrystallization temperature of $1750^{\circ} \mathrm{F}$ (as tested $1987^{\circ} \mathrm{F}$ and $2073^{\circ} \mathrm{F}$ ) but below the NDT (Figures 21, 22)..$^{35}$

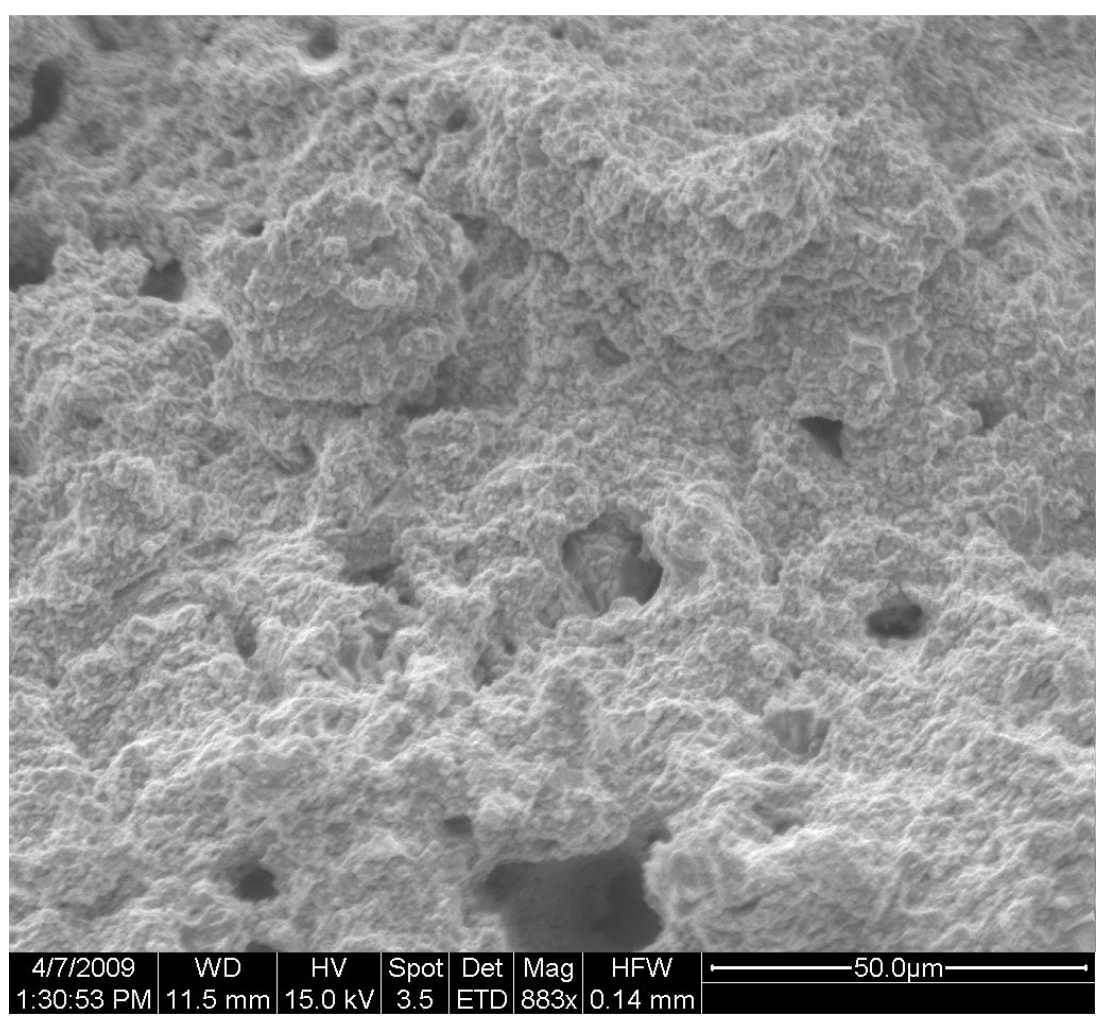

Figure 21: As the on-heating temperature increases $\left(1987^{\circ} \mathrm{F}\right)$, the grains become more refined, before coarsening, and fracture becomes more brittle (\%AR of $65.93 \%)$. 


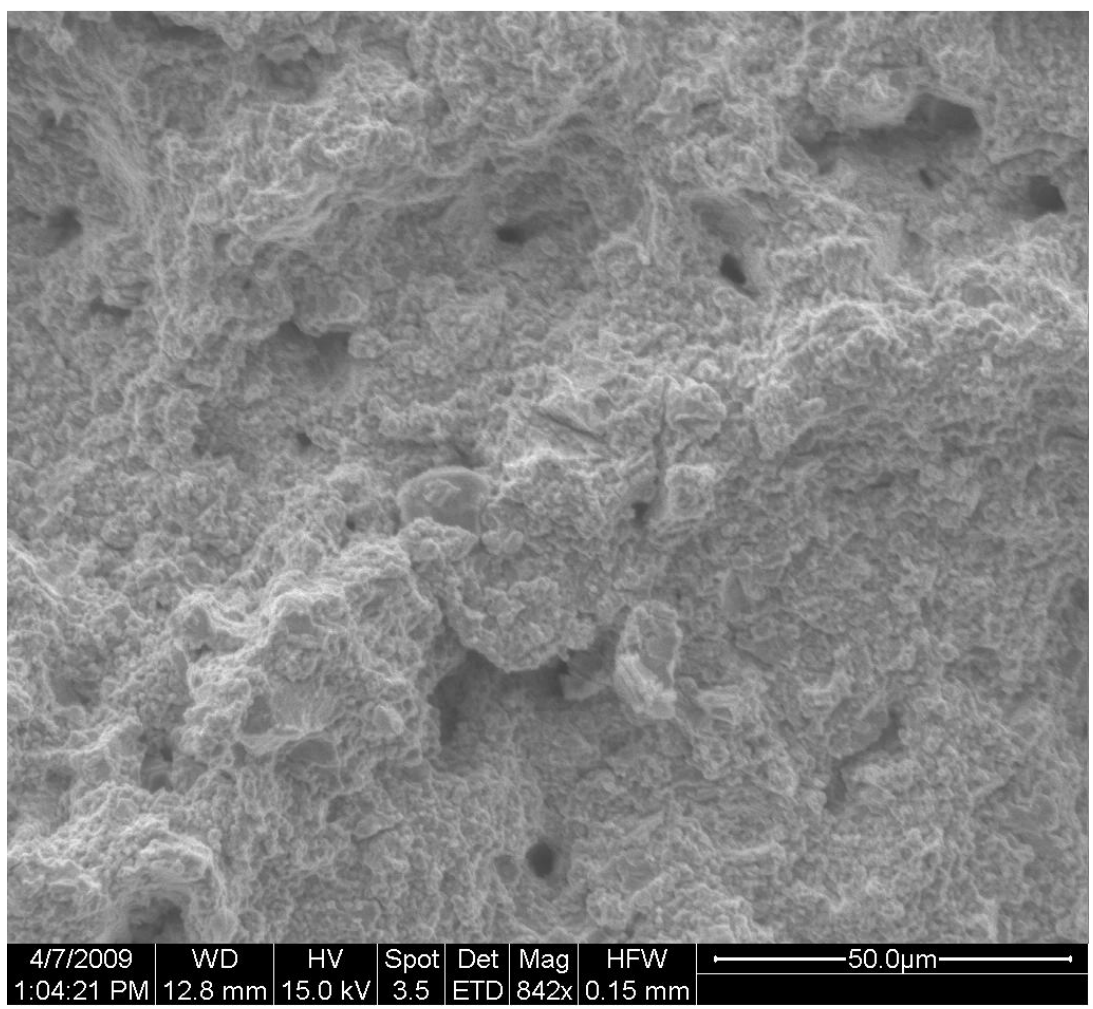

Figure 22: Further embrittlement and continued refinement as the on-heating pull temperature increases $\left(2073^{\circ}\right.$ F), but stays below the NDT (\%AR of $57.14 \%$ ).

After recrystallization, the grains begin to coarsen, with an increasing temperature; along with coarse grains, samples pulled above the NDT should demonstrate intergranular, brittle fracture (Figure 23). 


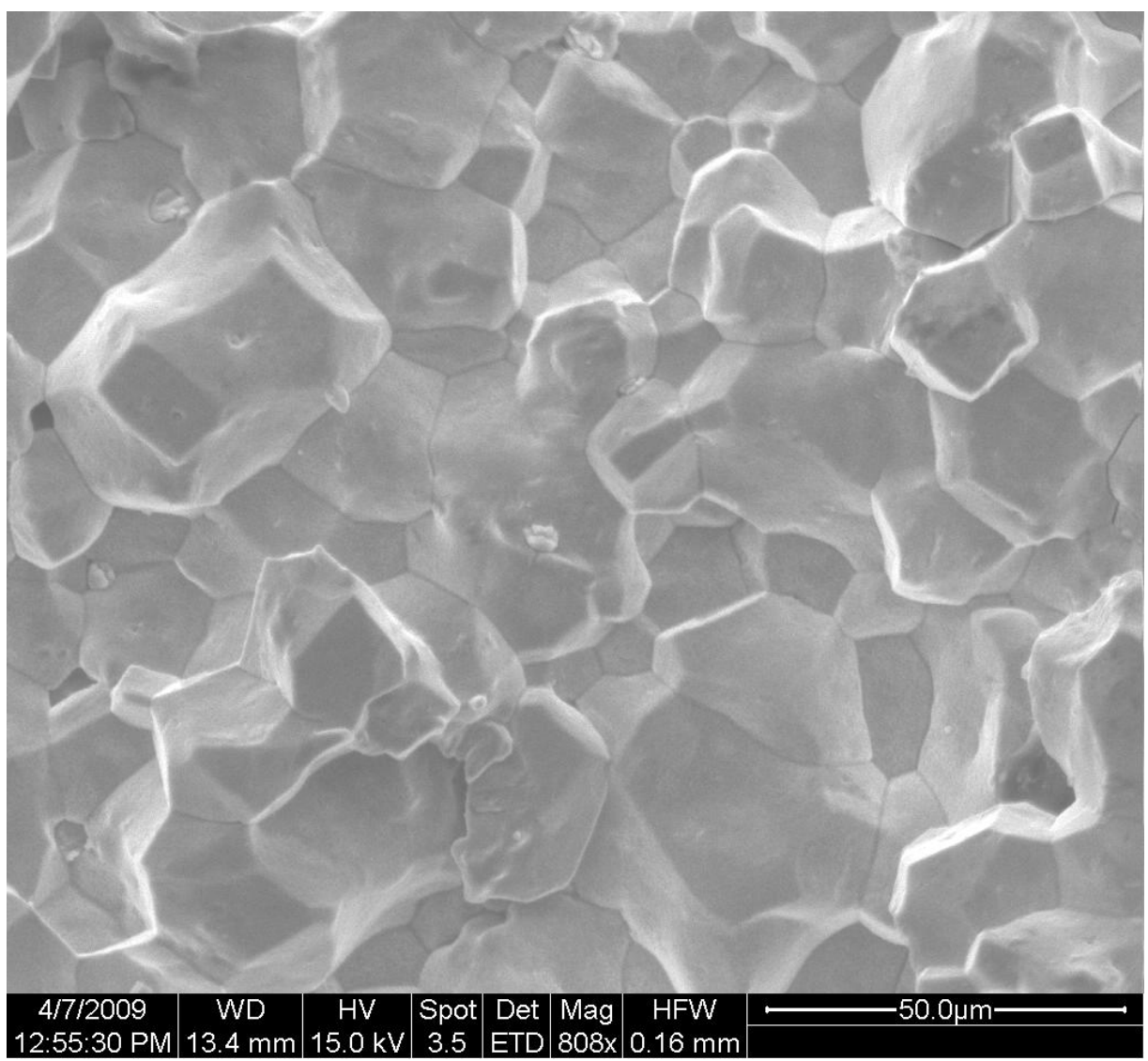

Figure 23: As the pull temperature $\left(2188^{\circ} \mathrm{F}\right)$ passes the NDT the grains become coarse with a significant degree of intergranular brittle fracture (\%AR of $0.80 \%)$.

If Figure 23 is compared to either Figure 21 or Figure 22 the dramatic increase in grain size is noticed. Another feature noticed in Figure 23 is the intergranular failure demonstrating a lack of microvoid coalescence evident of the ductile fracture. This lack of ductile fracture would lead to the conclusion that the material is becoming more brittle, reinforcing the conclusion noticed by the on-heating curve in Figure 19.

Another feature noticed during the evaluation of the on-heating post NDT fracture sample was the agglomeration of precipitates along the grain boundaries (Figure 24). These precipitates are expected to agglomerate at the elevated temperatures as they are the reason that Inconel is loses its strength at the nil strength temperatures. 


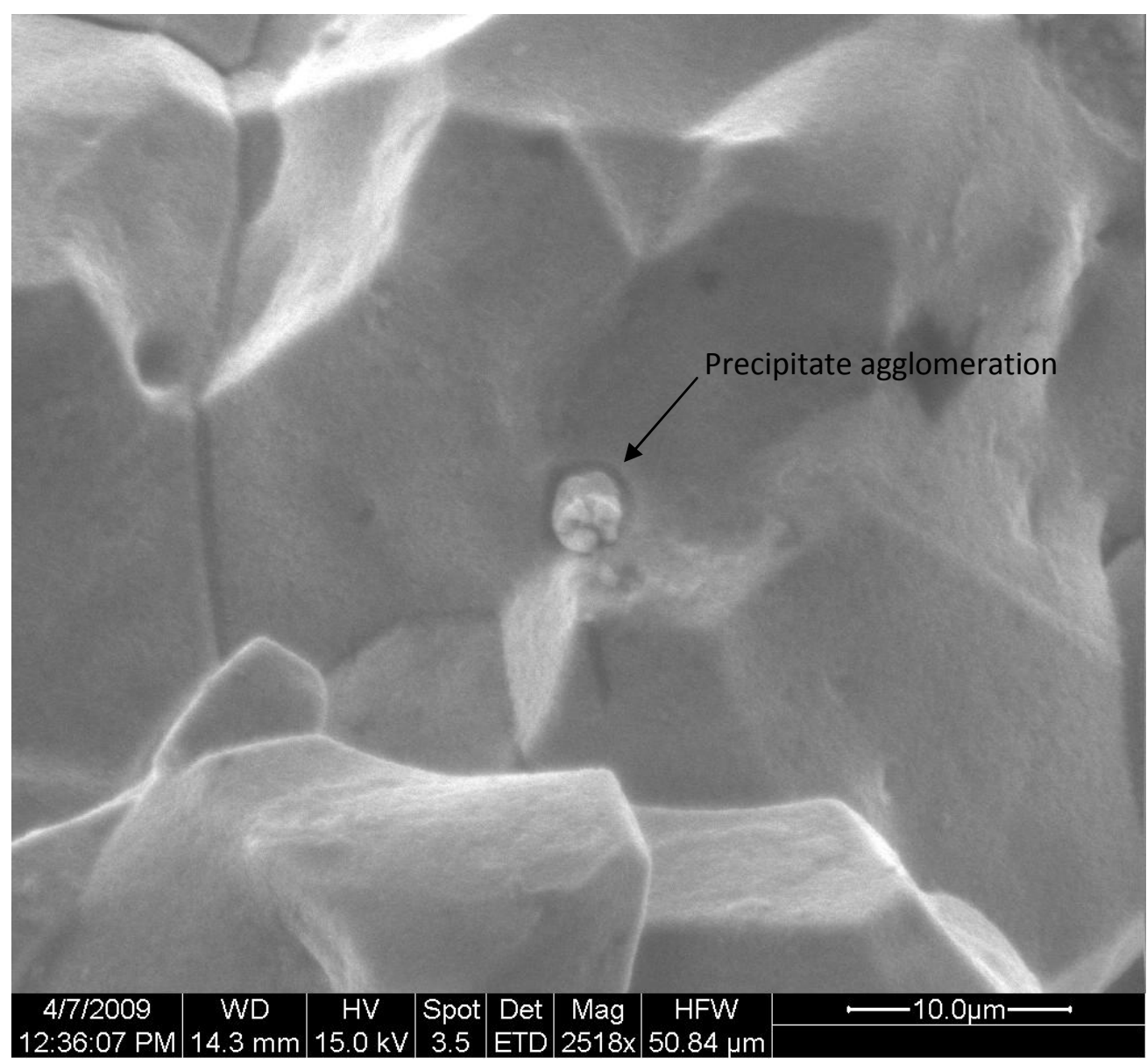

Figure 24: Apparent precipitate agglomeration along grain boundaries are the primary reason Inconel 718 cracks after repair welds.

The precipitate agglomeration along grain boundaries is expected in order for the Inconel 718 to form cracks after weld repair. These precipitates have been noted in other studies and are not expected to effect the results of this study.

After the NDT, the pull temperature is increased to the NST. One noticeable feature with the NST samples is the evidence of non-defined grains (Figure $25 \mathrm{a}, \mathrm{b}$ ). This difference is even more noticeable when comparing intergranular fracture surface seen in Figure 23 with the lack of grain definition seen in Figure 25b.

It was explained earlier that as the liquid forms around the grains, the material retains some of its strength due to capillary effects. As the percentage of liquid increases, the capillary effects are unable to support the forces on the system. If the sample is then pulled at this 
temperature, the fracture surface

would not resemble the

intergranular surface due to the

presence of the liquid. This trend is

seen here in Figure 25 where the

NST fracture surface failed during a

gross melting of grain boundaries

that solidified after fracture. As a

result, the NST fracture surface

shows evidence of post fracture

liquid cooling.

From the lack of definition

seen along the grain boundaries

(when compared to lower

temperatures) along with the low

strength measured at the pull

temperature, it can be concluded

that the sample does show evidence

of liquid present when heated.

After the NST, the test

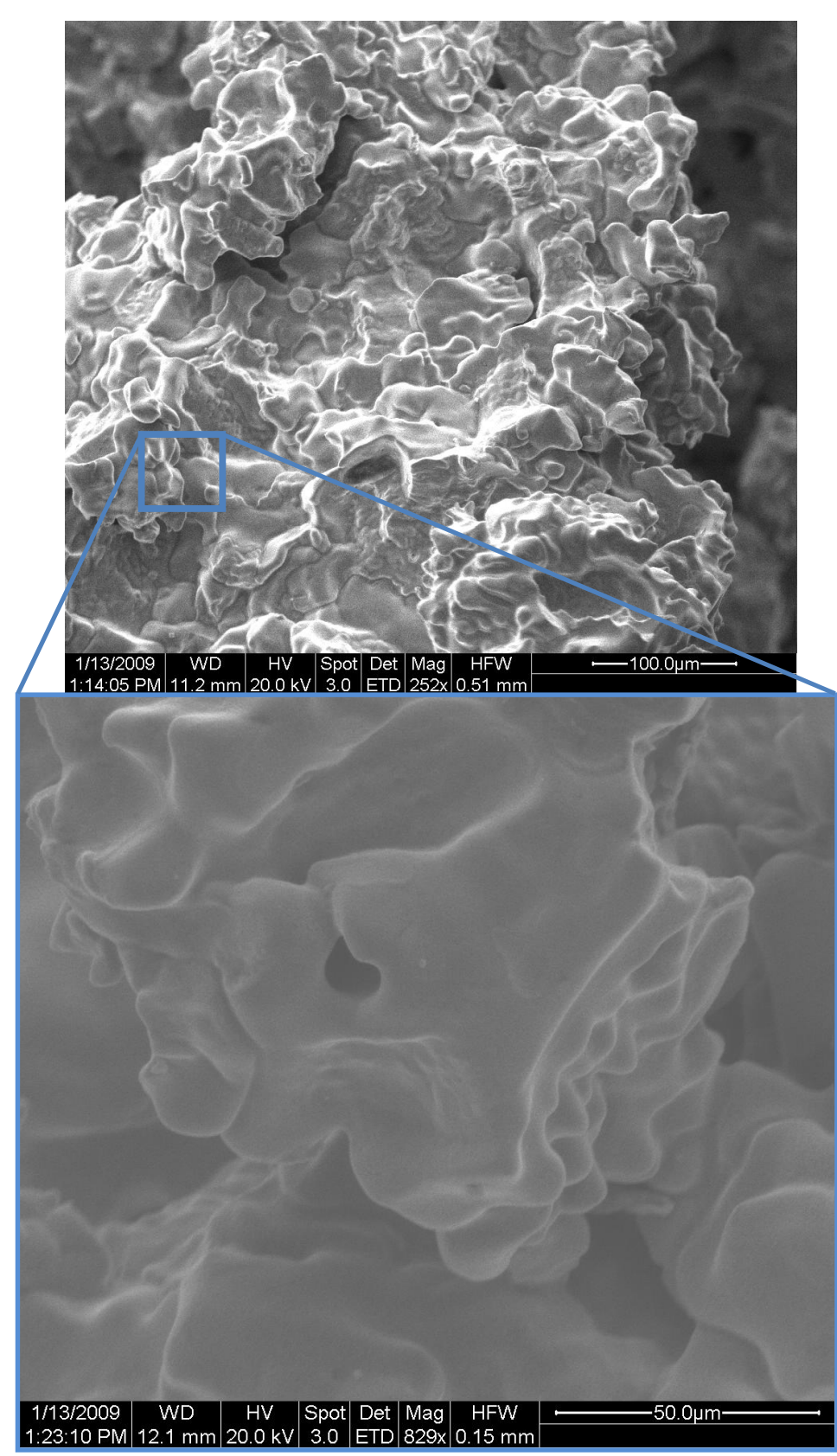

Figure 25: The lack of grain definition, when compared to Figure 24, demonstrates an inability to support its structure and the possible formation of a liquid phase as expected at the NST. (\%AR of $0.00 \%)$.

samples were tested on-cooling; controlled heating up to the NST and then cooled, again in control, to the designated pull temperature. As the samples were cooled, the material begins to recover the lost ductility. This brittle to ductile transition is noticed when the pull temperatures 
go below the DRT. The DRT however, is much lower than the NDT and the evaluated samples demonstrate this trend. This behavior was evident in the fracture surfaces of the on-cooling samples evaluated above the DRT. The sample evaluated at higher temperatures than the DRT of $1925^{\circ} \mathrm{F}$, showed evidence of coarse grains with similar lack of grain definition as seen in the NST samples in Figure 25 (Figure 26).

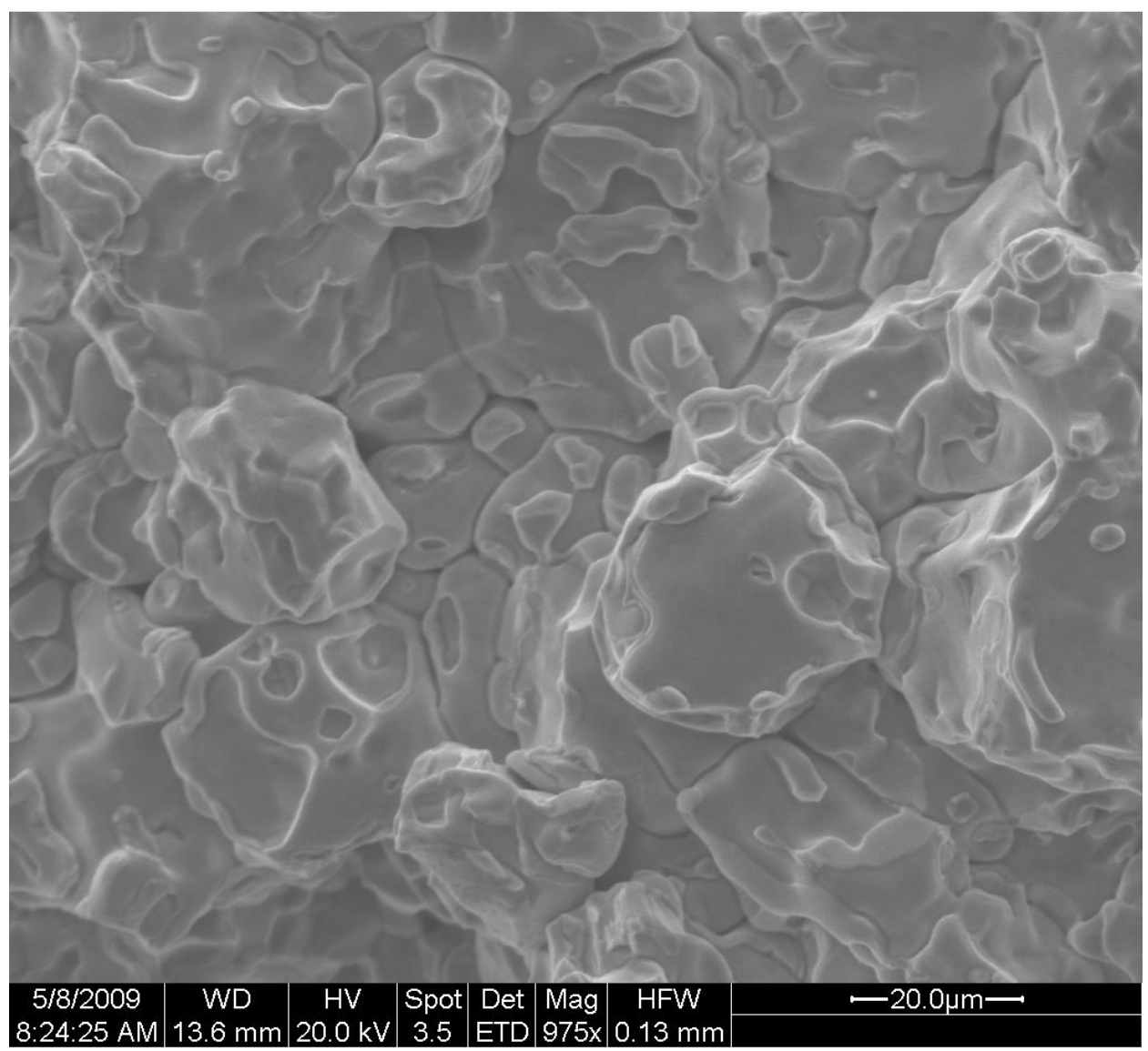

Figure 26: The on-cooling fracture surface $\left(2130^{\circ} \mathrm{F}\right)$ showed evidence of non-defined grains as seen in the NST samples visually showing samples did not recover ductility until well below NDT (\%AR of $0.80 \%$ ).

As the on-cooling pull temperature dropped, the lack of microvoid coalescence as well as the lack of definition seen within the grains is evident at lower temperatures, $1930^{\circ} \mathrm{F}$ (Figure 27). These two factors, at this lower temperature, can be explained by the phenomenon known as constitutional liquation. 

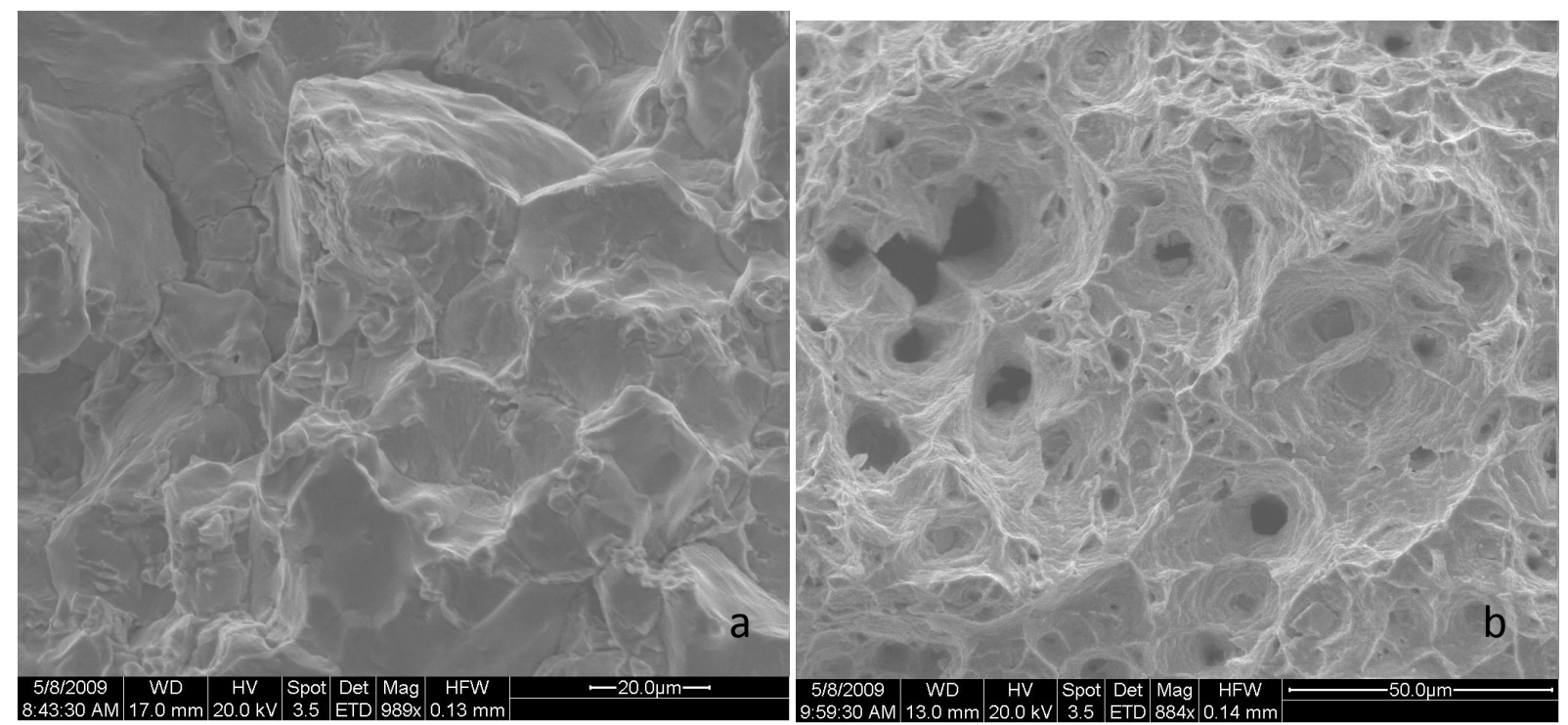

Figure 27: As the on-cooling temperature decreased $\left(1930^{\circ} \mathrm{F}, \mathrm{a}\right)$, it continued to show little evidence of brittle fracture leading to the conclusion that a persistent liquid phase was present around grain boundaries (\%AR of $0.00 \%)$. This lack of ductile behavior is noticed when compared to more ductile samples evaluated at lower temperatures $\left(1680^{\circ} \mathrm{F}\right.$ with \%AR of $\left.71.90 \%, \mathrm{~b}\right)$.

As evident in Figure 27, the material still has not recovered its ductility as there is a lack of evidence of the microvoid coalescence that is more evident in the samples below the DRT. Another conclusion that can be drawn from this image is the presence of the liquid phase as evident by the lack of grain definition similar to that seen in Figure 25. The grains themselves also show the lack of grain definition that occurs at the higher pull temperatures.

As the pull temperature $\left(1870^{\circ} \mathrm{F}\right)$ dropped below the DRT $\left(1925^{\circ} \mathrm{F}\right)$, the fracture surface began to show evidence of the microvoid coalesence indicative of ductile fracture (Figure 28). This behavior was even more evident at the cooler pull temperatures, $1626^{\circ} \mathrm{F}$ (Figure 29). 


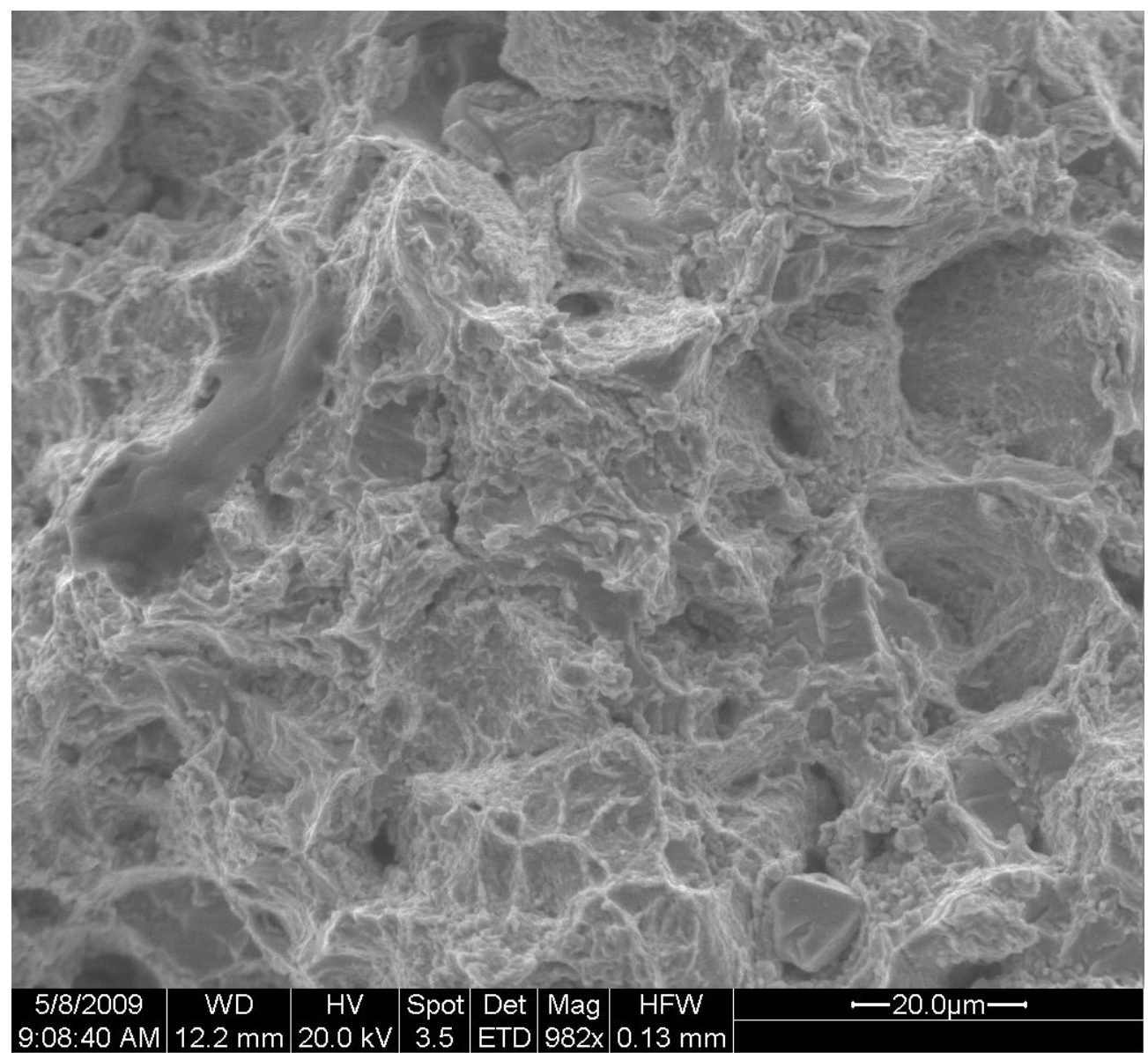

Figure 28: On-cooling samples did not show evidence of ductile fracture until the pull temperature fell well below the NDT. The sample seen here, $1870^{\circ} \mathrm{F}$, began to show evidence of microvoid coalescence showing evidence of ductility recovery (\%AR of $53.93 \%)$. 


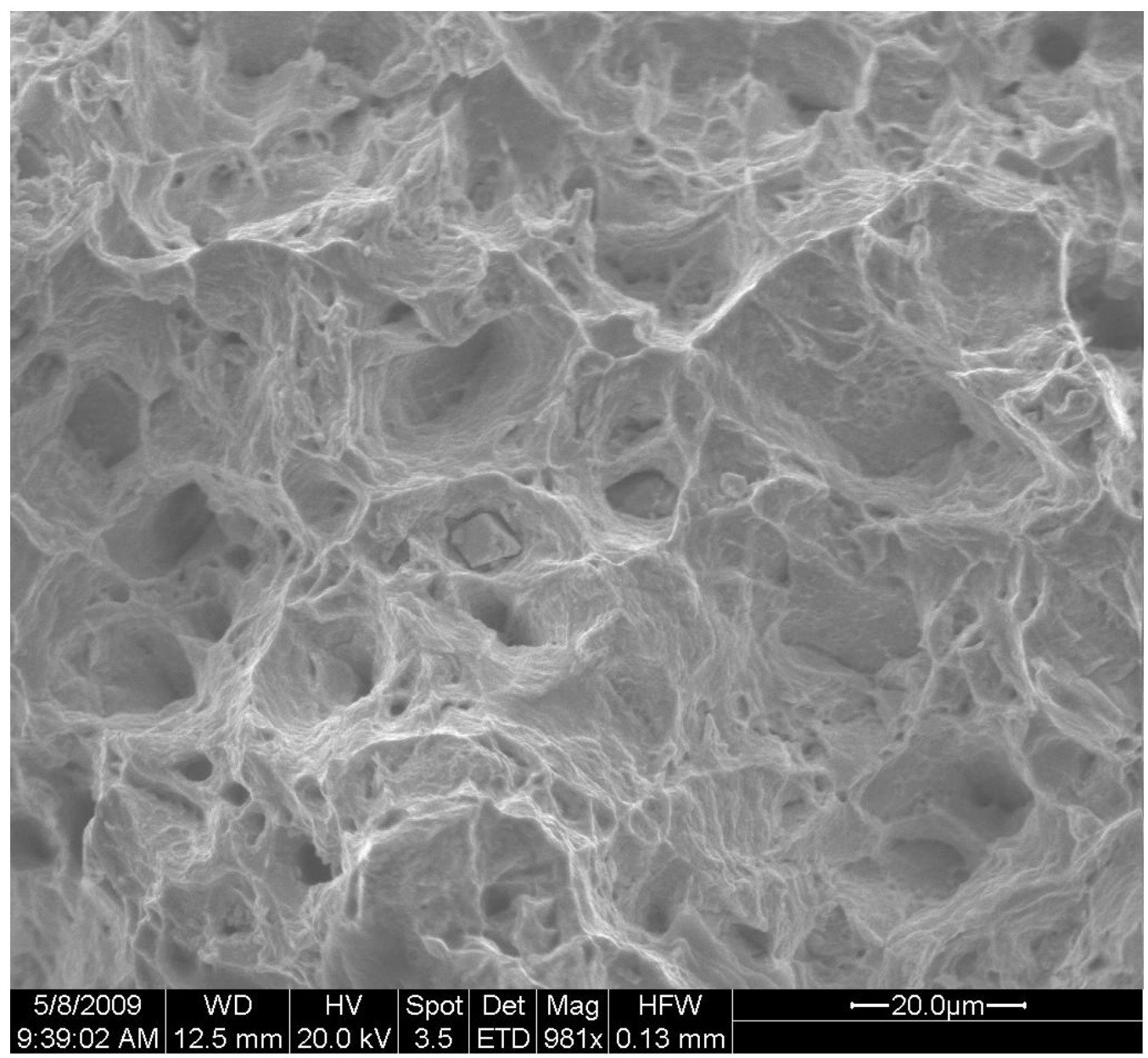

Figure 29: On-cooling samples began showing similar fracture mechanisms to its on-heating equivalents after significant cooling $\left(1626^{\circ} \mathrm{F}\right.$ with \%AR of $\left.61.25 \%\right)$.

As outlined in the objectives, the goals of this study were threefold. The goals of the Varestraint test were to determine the threshold strain, saturation strain, and MCL of the material. It was determined that the Inconel 718 had threshold strain of $0.5 \%$, a saturation strain of $2 \%$ with a maximum crack length of $0.65 \mathrm{~mm}$. The Gleeble test was able to show changes in microstructure as the material was heated and cooled through a typical weld thermal cycle. The goal of the Gleeble test was to determine the NDT, NST and DRT which were $2182^{\circ} \mathrm{F}, 2273^{\circ} \mathrm{F}$, and $1925^{\circ} \mathrm{F}$, respectively. Since these characteristics fit with the evaluated fracture surfaces it should be possible to determine the weldability of this material by comparing the results from this study to relevant literature. 


\subsection{Review of Objectives}

\section{Chapter 4 Discussion}

The tests performed in this study were conducted in order to satisfy two of the three objectives outlined in Chapter 3. These two objectives were: (1) determine the threshold strain, saturation strain, and maximum crack length using Varestraint testing techniques, and (2) use the Gleeble to measure the nil strength, nil ductility, and ductility recovery. The third objective, determine weldabilty of Inconel 718 by relating Varestraint and Gleeble results with relevant literature, will be discussed here.

\subsection{Comparison of Results with Relevant Literature}

The trends in the Varestraint and Gleeble results from this experiment follow closely with those seen in the extensive literature relevant to the weldability of Inconel 718. A study conducted by R. Chhatre used both the Varestraint and Gleeble testing apparatuses to compare Inconel 718 and two other nickel based alloys. ${ }^{36}$ The methodology in the Chhatre study was similar to this study's methodology for Varestraint and Gleeble testing. As outlined in Chapter 3 , the Inconel 718 of this study had a threshold strain of $0.5 \%$ and a saturation strain of $2 \%$. This is similar to the Chhatre results with a threshold strain of $0.25 \%$ and a saturation strain of $2 \%$. As explained, the saturation strain is important when classifying the hot crack susceptibility as this is the strain where a material's crack behavior is independent of strain. The saturation strain of this study matches well with Chhatre's earlier work.

Similarly, the Gleeble data of this study was compared with the published data in the Chhatre study. The temperatures of interest in this study were the NDT, NST, and DRT. These measured values were; a NDT of $2182^{\circ} \mathrm{F}$, NST of $2273^{\circ} \mathrm{F}$, and a DRT of $1925^{\circ} \mathrm{F}$. The Chhatre study saw similar values for these characteristic temperatures; the NDT was $2110^{\circ} \mathrm{F}$, the NST 
was $2280^{\circ} \mathrm{F}$, and the DRT was $1900^{\circ} \mathrm{F}$. The similarities in methodology and results from this study and the Chhatre study providing strong evidence of repeatability.

\subsection{Comparison of Weldabilty with Relevant Literature}

According to the literature, the most critical factor that influences the recovery of ductility during the on-cooling test is the peak temperature. ${ }^{37}$ In other studies, the NDT, NST, temperatures between the NST and NDT, as well as other arbitrary temperatures have been used as the peak temperature. This study used the NST as the peak temperature as it presented itself for better comparison of relevant literature. Since a variety of temperatures can be used, comparison of weldability tests has proven difficult. Therefore, several methods have been developed for interpreting weldability tests that use Gleeble or Varestraint test results. These criteria that determine if a material is weldable include:

1. matching on-heating curves with $\mathrm{H} 1$ curves then matching on-cooling curves with $\mathrm{C} 1$ or C2 curves;

2. a small rate of ductility recovery during on-cooling defined by a smaller temperature range in which ductility is recovered when compared to other materials;

3. a small temperature range between the NST and the DRT through comparison;

4. finally, a shorter maximum crack length when compared to other materials

Many other methods exist for determining the weldability of various alloys but will not be used in this study. This is because the methods selected used a peak temperature of the NST as the peak temperature, where the other criteria do not.

\subsubsection{Classification of On-Heating and On-Cooling Curves - Nippes Criterion}

Soon after the development of the Gleeble, Nippes proposed a criteria relating on-heating and on-cooling curves to liquation crack susceptibility. After extensive comparison studies of 
nickel alloys, Nippes concluded that the hot cracking behavior of materials could be classified into two on-heating and three on-cooling groups (Figure 30). ${ }^{38}$

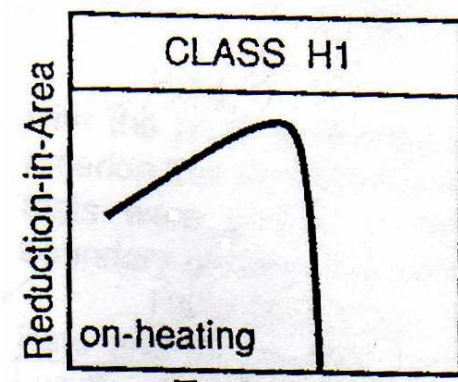

Temperature

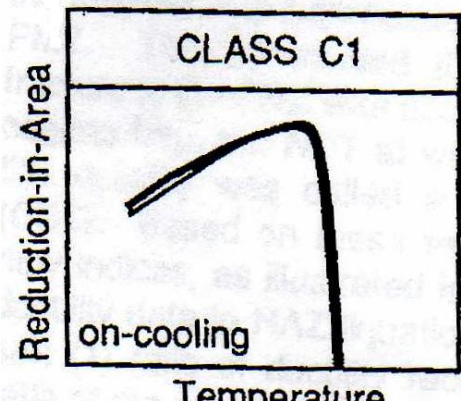

Temperature

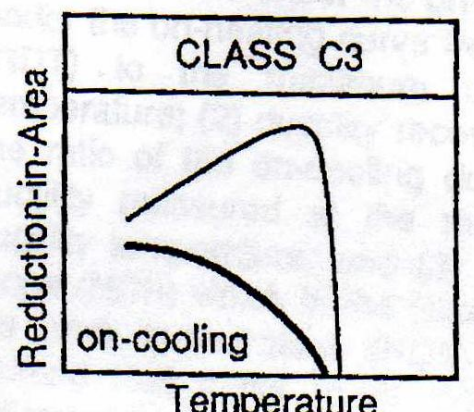

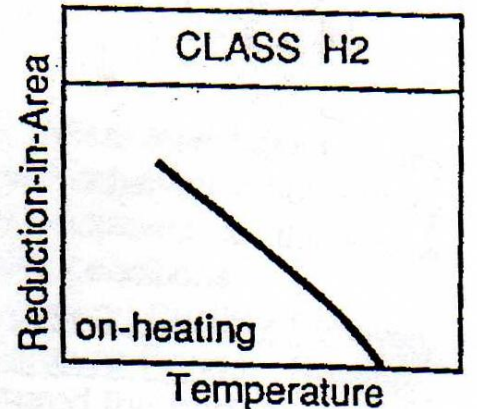

Temperature

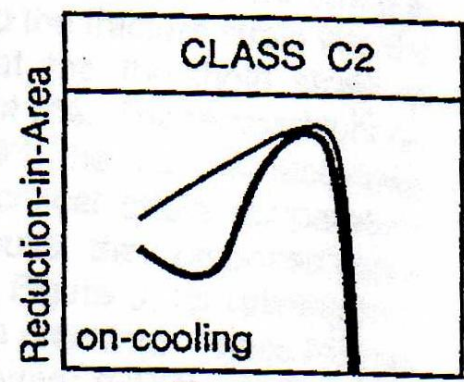

Temperature

Figure 30: These curves are used as a method to classify weldability of a material. The on-heating curve H1 means the material may be weldable but must then compare on-cooling curves. The on-cooling curve C1 and C2 mean the material is readily weldable. For on cooling curves, the thinner line is the super imposed $\mathrm{H} 1 \mathrm{curve}^{38}$

According to their research, when a material's on-heating curve matches the $\mathrm{H} 1$ curve, the material must then be characterized against the cooling curve. Class $\mathrm{H} 2$ materials are known to have a high susceptibility to form liquation cracks. If the cooling curve is listed as Class $\mathrm{C} 1$ or $\mathrm{C} 2$ then the material does not favor liquation cracking but if the material is Class $\mathrm{C} 3$, then the material usually has a high susceptibility to form liquation cracks. After comparisons with 
Inconel 718, the on-heating curve most resembles an $\mathrm{H} 1$ curve while the on-cooling curve most resembles a C2 curve (Figure 31 ).

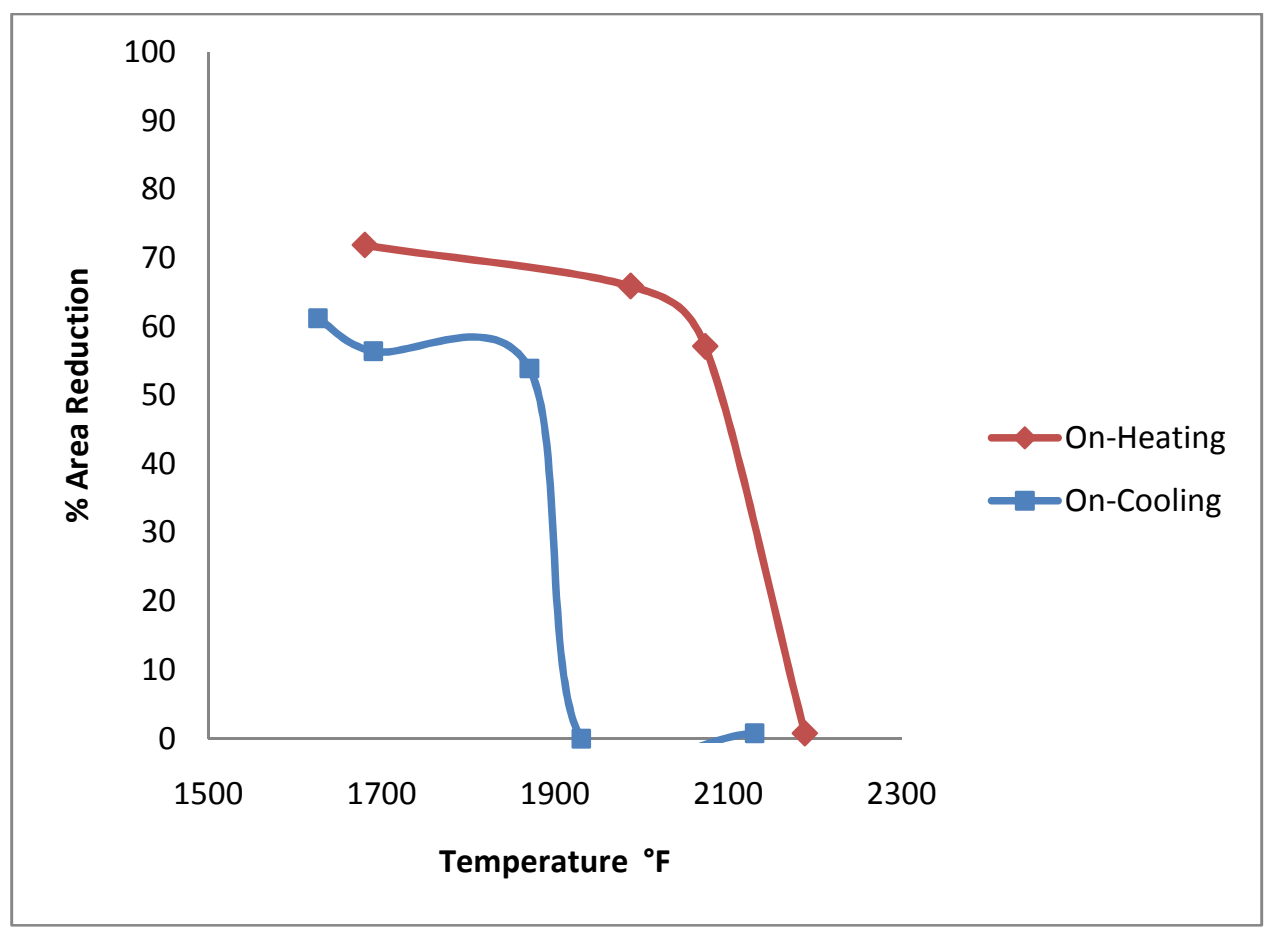

Figure 31: By comparing the curves seen here developed from Gleeble testing of the Inconel 718 sample with the curves outlined by the Nippes criterion, weldability can be determined. The on-heating curve matches best to $\mathrm{H} 1$ while the on-cooling curve matches best with C2 leading to the conclusion that Inconel 718 is weldable.

As originally stated, the on-heating curve had to match $\mathrm{H} 1$ and the on-cooling curve had to match $\mathrm{C} 1$ or $\mathrm{C} 2$ in order for a material to be considered weldable. Based on the above comparison between the curves defined by the Nippes' criterion in Figure 30 and the tested curves in Figure 31, the Inconel 718 tested in this study is readily weldable.

\subsubsection{Rate of Ductility Recovery On-Cooling - Duvall Criterion}

One problem with the previous classification system is that the curves do not fully match the classification curves. This can be seen with the Inconel's on-cooling curve which does not exactly match the $\mathrm{C} 1$ or $\mathrm{C} 2$ curves but falls slightly between. Other problems arise when comparing the on-heating curves with other literature. According to some sources, the on- 
heating behavior of a material is irrelevant because liquation cracking occurs during weld cooling and not heating. ${ }^{39}$ Since the on-cooling curve is more important than the on-heating curve, the peak temperature reintroduces itself as an important factor. Duvall states that using the NDT as the peak temperature for the on-cooling curve restricts comparisons for liquation cracking sensitivity for materials. Duvall also states that the rate of ductility recovery can only be measured when cooling begins (i.e., the peak temperature) with the NST as ductility recovery is unobservable at the NDT.

The Duvall criterion states that the amount of ductility recovery and the temperature range at which this recovery occurs are the best ways to evaluate a material's sensitivity to produce liquation cracking. ${ }^{40}$ The temperature range in which ductility is recoveredcan be determined graphically by comparing the Inconel 718's tempreature range with the alloys studied in the original Duvall article (Figure 32). ${ }^{41}$ 


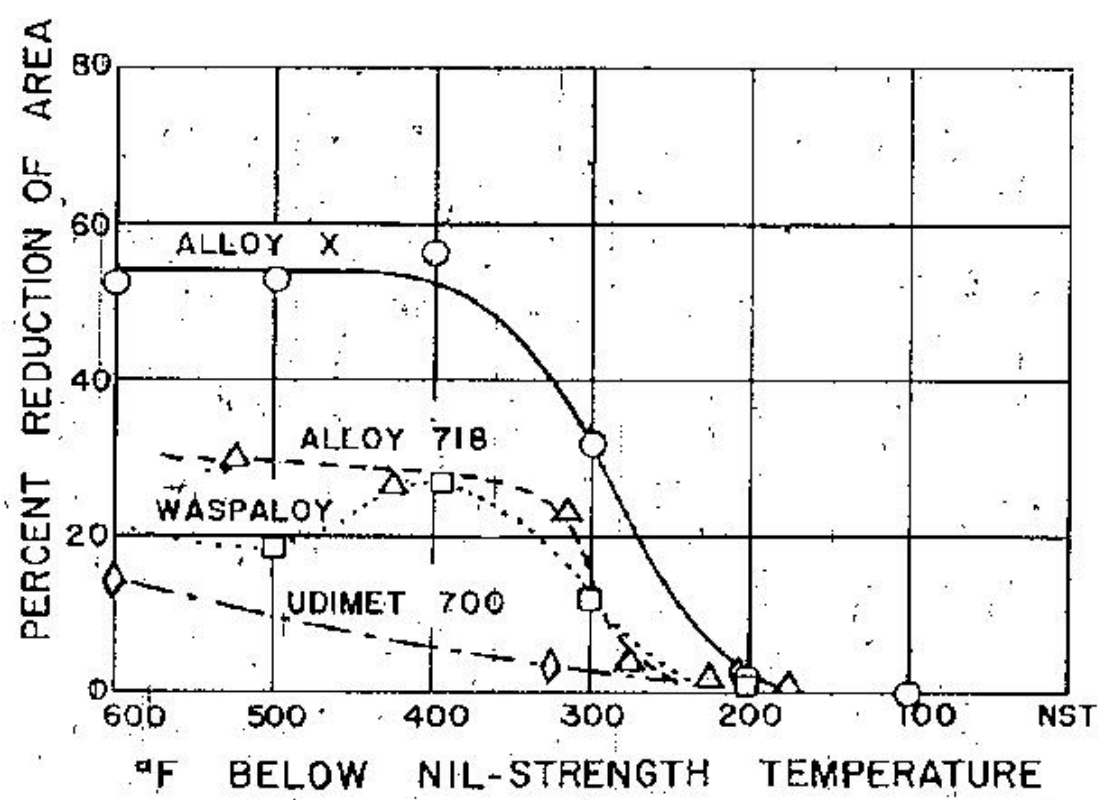

Figure 32: Duvall tested four different alloys to determine the relationship between ductility recovery and weldability. He determined a higher max recovery and smaller recovery temperature range, the more readily weldable the material. According to his results, the Alloy 718 is the most weldable with a max recovery of $55 \%$ and a recovery range of approximately $200^{\circ} \mathrm{F} .^{40}$

From the above comparison, Alloy $\mathrm{X}$ recovers more ductility than the other three materials meaning Alloy $\mathrm{X}$ is the most readily weldable material. The Inconel 718 sample is then compared to Alloy $\mathrm{X}$ to determine if it is more or less weldable. This comparison is made by plotting the Inconel 718 alloy measured percent area reduction against the degrees Fahrenheit below the NST (Figure 33). 


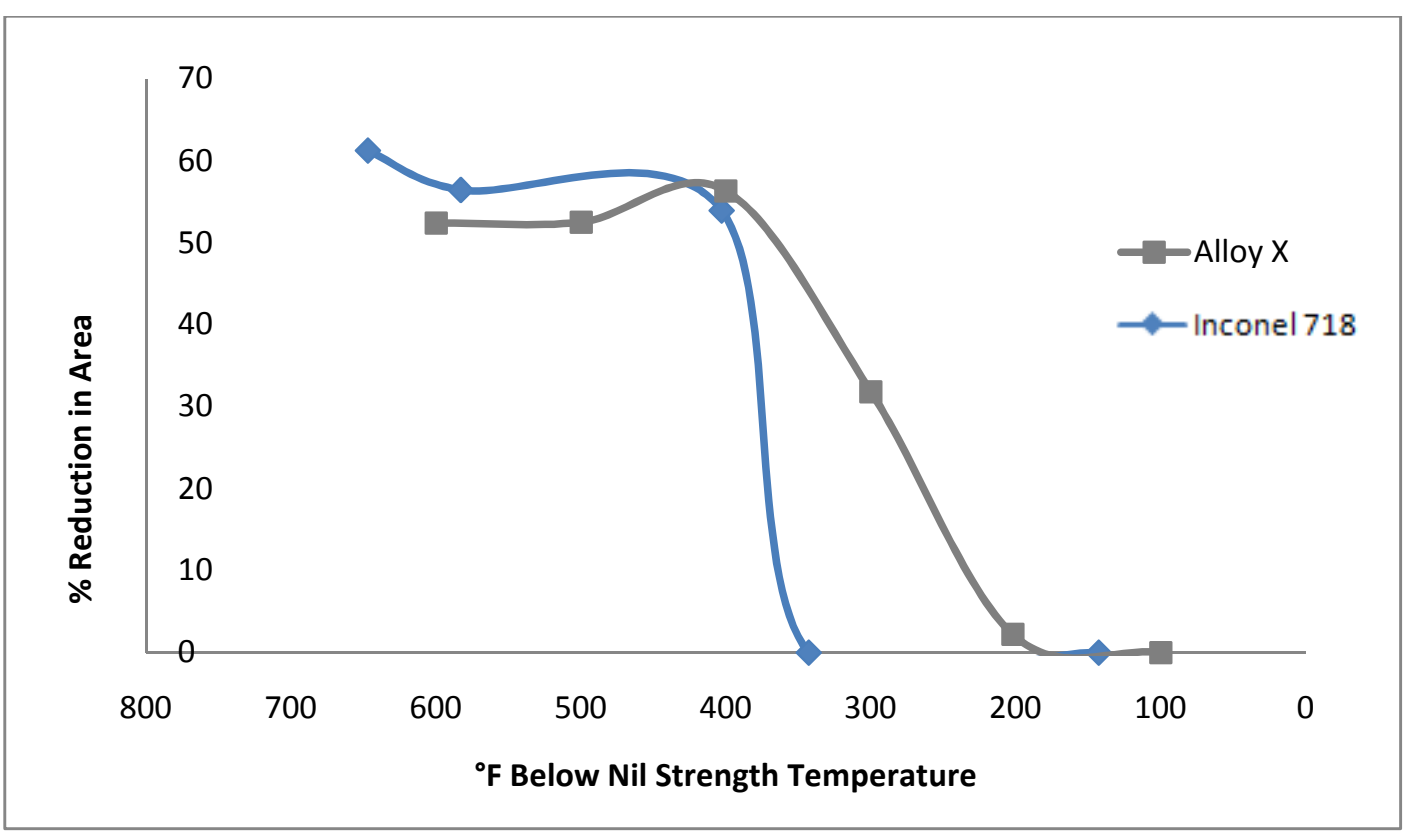

Figure 33: When compared to the alloys in Figure 32, the Inconel is more weldable as it appears to have a higher maximum recovery and a smaller temperature recovery range in roughly $100^{\circ} \mathrm{F}$, compared to Alloy $\mathrm{X}$ of $200^{\circ} \mathrm{F}$.

By observing the trends, it can be determined that the Inconel 718 is going to be the most resistant to liquation crack formation when compared to the four Duvall alloys. According to the Duvall, Alloy X was the least likely to form liquation cracks since it had the fastest ductility recover rate. Through comparison, Inconel 718 should be even more resistant to liquation cracks as it regains ductility in approximately half the temperature of Alloy $\mathrm{X}\left(\approx 100^{\circ} \mathrm{F}\right.$ versus $200^{\circ} \mathrm{F}$, respectively). The criteria stated that for a material to be considered weldable, it had to have a faster rate of recovery as well as a large value for the magnitude of ductility recovery. From the above comparison, Inconel 718 is weldable since it has a faster recovery rate and recovers more of its ductility when compared to other high strength Ni based alloys.

\subsubsection{Temperature Range Between the NST and the DRT - Williams Criterion}

As seen with the other criteria for classifying liquation cracking, the most important and varied parameter is the peak temperature for the on-cooling test. The Williams criterion is a 
straightforward and the most commonly used test to determine liquation crack susceptibility (weldability) of a material. The test compares the range of temperature, during on-cooling, between the NST and the DRT. The criterion states the smaller this range, the less susceptible the material is to form liquation cracks (more weldable). This would make sense as a lower temperature range would mean the material would have less time, during cooling, to form cracks during Stage 3 (Borland's theory).

In the study performed by Williams, four austenitic stainless steel samples were compared with the resultant temperature ranges resulting as $80,320,340$, and $500^{\circ} \mathrm{F}{ }^{42}$ The Inconel 718 in this experiment had a NST - DRT range of $348^{\circ} \mathrm{F}$. When evaluating Inconel 718 for the Williams criterion the Inconel 718 is the fourth most weldable material; or three of Williams' four tested materials are more weldable. Though the tested Inconel specimen is more susceptible to forming hot cracks than three other specimens, it does not mean Inconel 718 is a poor welding choice. This test shows that the Inconel 718 is simply less weldable than three of the highly weldable stainless steel samples chosen in the Williams study. It is important to remember that weldability is only one parameter considered when selecting a material for a given operation and this test shows that there are more weldable materials than tested Inconel.

\subsubsection{Comparison}

The maximum crack length is a value that is measured after Varestraint testing. The value is determined by measuring the crack length of the sample at the saturation strain; the strain where the MCL appear to level out. The Inconel 718 sample tested in this experiment had a saturation strain at $2 \%$ with an average MCL of $0.65 \mathrm{~mm}$. The MCL can then be used to compare to other alloys to determine crack susceptibility. Although a variety of factors affect the 
likelihood a material will fail after cracking, in general, the larger the MCL the more likely the material is to form hot cracks. ${ }^{43}$ One study compares Incoloy 903 and 909 and determines the MCL of these alloys to be roughly $0.7 \mathrm{~mm}$ and $1.3 \mathrm{~mm}$ respectively (Figure 34). If the Inconel 718 is compared to these two nickel-based superalloys, the Inconel 718 has an equal to or better than ability to resist hot crack formation. This test is an easy method that can be used to compare known alloys with experimental alloys.

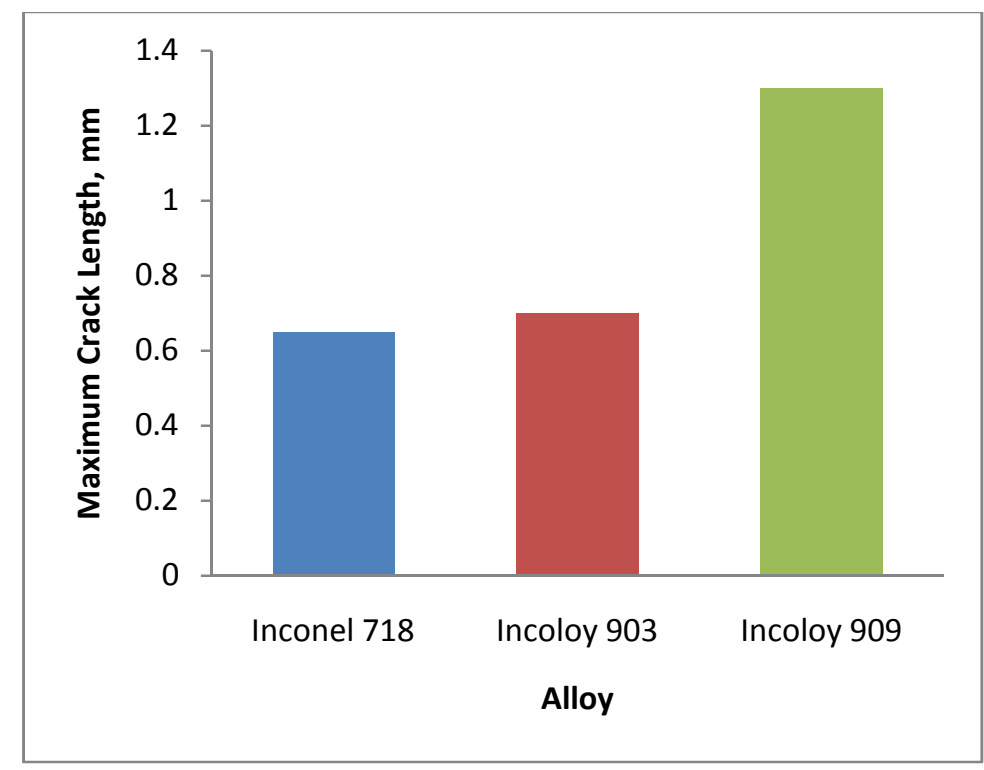

Figure 34: By comparing the MCL of various samples critical crack range can be developed for materials to prevent hot cracking. The shorter the $\mathrm{MCL}$ developed at the saturation strain for a material, the less susceptible the material is to form hot cracks. The Inconel 718 sample had the shortest MCL making it the most weldable.

The criterion for this test stated that the smaller the MCL at the saturation strain, the more weldable the material. In this case, the Inconel 718 had shorter crack lengths at the saturation strain than both of the compared Incoloy alloys showing improved weldability of Inconel 718 when compared to the Incoloy alloys. 


\section{Chapter 5: Conclusion}

In order to determine weldability of an alloy, certain characteristics need to be measured. These characteristics are the saturation strain, maximum crack length, nil ductility temperature, nil strength temperature, and ductility recovery temperature. The first two characteristics can be determined from a Varestraint weldability test. For the tested Inconel 718 specimen, the saturation strain was $2 \%$ with a maximum crack length of $0.65 \mathrm{~mm}$. The final three criteria can be measured using a Gleeble weld simulator. The Inconel 718 was found to have a NDT of 2182 ${ }^{\circ} \mathrm{F}$, an NST of $2273^{\circ} \mathrm{F}$, and a DRT of $1925^{\circ} \mathrm{F}$. The changes in microstructure are then analyzed and compared with theory. From this analysis, the samples appeared to follow Borland theory as well as constitutional liquation theory. These values can then be compared to relevant literature to determine weldability.

As expected, Inconel 718 appears to be readily weldable as it shows greater than or equal to weldability in three of the four proposed criteria outlined in Chapter 4. The Nippes criterion dictated weldability when the on-heating curve of the sample matched the H1 curve and the oncooling sample matching either the $\mathrm{C} 1$ or $\mathrm{C} 2$ curves. The Nippes criterion is successful in generalizing weldability but is not fully accurate because the curves of the tested sample did not match completely. This led to the next comparison to test for weldability, the Duvall criterion: materials with more and faster ductility recovery during on-cooling are less susceptible to form hot cracks. According to the Duvall Criterion, the Inconel 718 sample proved more weldable than the samples tested by Duvall including his most weldable alloy, Alloy X. The Inconel sample regained its ductility in approximately half the temperature range than the most weldable Duvall alloy. Lastly, the tested Inconel 718 showed greater weldability with the MCL comparison which stated materials with shorter MCL at the saturation strain were readily 
weldable. The Inconel sample was more weldable than the two samples proposed in the previous study as the Inconel had the shortest MCL ( $0.65 \mathrm{~mm}$ versus $0.7 \mathrm{~mm}$ and $1.3 \mathrm{~mm}$ respectively). These three studies showed that the Inconel 718 was weldable. One comparison test, however, showed that the Inconel sample was less weldable than a majority of the compared materials. The Williams test stated that the smaller the range between the NST and the DRT the more weldable the material. The tested Inconel sample was less weldable than three of the four stainless steel samples tested in the Williams test. Though the compared steels showed more weldability than the Inconel, this should not be used as a deterrent when selecting Inconel 718 as the previous three tests showed that the Inconel was weldable. 


\section{Chapter 6: Recommendations for Future Work}

The Varestraint test is useful in predicting the weldability of metals because it performs actual welds on the sample rather than the simulation of weld zones as seen in the Gleeble. By further study of the Varestraint test specimens, more accurate criteria could be developed to predict hot cracking. One area of focus derived from this study could be an in-depth analysis of the microsturctural changes within Varestraint samples and its relation to the length of the cracks created during testing. From welding theory, changes in microstructure are expected during welding. With current computer simulation programs it is possible to predict duration of these microstructure changes in given alloys under varying conditions. If more understanding of the effects microstructure changes have on developing hot cracks, these computer models can be updated to help predict hot crack formation.

Another study could focus on the effects that cause the second type of hot cracking, solidification cracking. This study focused on characterizing Inconel 718's ability to form the first type of hot cracking, liquation cracking. Further characterization will create better tools that can be used to predict the hot ductility behavior of Inconel 718. With a better understanding of the hot ductility behavior of this weldable alloy, more accurate prediction tools can be created.

Finally, the information gained from this study can be used as a base for future alloy comparisons. Since Inconel 718 is a well known, readily weldable alloy, it can be used as a good starting point for alloy development. If experimental alloys are developed, the information gained from this study can be used as a comparison tool in similar fashion the Inconel was compared to the criteria outline in Chapter 4. 


\section{Chapter 7: References}

${ }^{1}$ Randy, B. (n.d.). Superalloys: A Primer and History. The Minerals, Metals, \& and Materials Society. Retrieved May 2009, from http://www.tms.org/Meetings/Specialty/Superalloys2000/SuperalloysHistory.html ${ }^{2}$ Bhadeshia, H. K. (n.d.). Nickel Based Superalloys. University of Cambridge: Department of Materials Science and Metallurgy. Retrieved May 2009, from http://www.msm.cam.ac.uk/phasetrans/2003/Superalloys/superalloys.html

3 Davis, J. (2000). Nickel, Cobalt, and Their Alloys. Materials Park: ASM International.

${ }^{4}$ Davis, J. (1997). Heat-Resistant Materials (pp. 221-254). Materials Park: ASM International.

${ }^{5}$ Smith, W. (1993). Structure and Properties of Engineering Alloys (pp. 499-535). McGraw-Hill Inc.

${ }^{6}$ Ojo, O., Richards, N., \& Chaturvedi, M. (2004). Liquid film migration of constitutionally liquated $\gamma^{\prime}$ in weld heat affected zone (HAZ) of Inconel 738LC superalloy. Scripta Materialia, 51, 141-146.

${ }^{7}$ Savage, W., \& Page, J. (1967). Effects of Constitutional Liquation in 18Ni Maraging Steel Weldment. Welding Journal, 12, 411.

${ }^{8}$ Ojo, O., \& Tancret, F. (2008). Clarification on "Thermo-Calc and Dictra simulation of constitutional liquation of gamma prime $\left(\gamma^{\prime}\right)$ during welding of Ni-base superalloys". Computational Materials Science, $X X$. Retrieved June 2009, from www.elsevier.com/locate/commatsci

${ }^{9}$ Acoff, V., \& Thompson, R. (2000). Characterization of Constitutional Liquid Film Migration in Nickel-Base Alloy 718. IBM Journal of Research and Development, 44(5), 668-679.

${ }^{10}$ Sivaprasad, K., Raman, S. (2008). Influence of Weld Cooling Rate on Microstructure and Mechanical Properties of Alloy 718 Weldments. Metallurgical and Materials Transactions, 39, 2115-2127.

${ }^{11}$ Mandziej, S. (2005). Testing for Susceptibility to Hot Cracking on Gleeble Physical Simulator. Hot Cracking Phenomena in Welds (pp. 347-376). Berlin: Springer.

${ }_{12}$ Shekin, I., Pilyushenko, V., \& Kochin, F. (1989). Nil-ductility transition temperature of ship plate and its connection with unit crack-propagation work. Strength of Materials, 21, 307-310.

http://www.springerlink.com/content/u502v8134570t59t/.

${ }^{13}$ Lampman, S. (1997). Weld Integrity and Performance. Materials Park. ASM International.

${ }^{14}$ Baeslack, W., Lin, W., \& Lippold, J. (1993). A methodology for quantifying HAZ liquation cracking susceptibility using the gleeble hot-ductility test. Welding Journal, 72(4), 135-153.

${ }^{15}$ Borland, J. (1960). Generalized theory of super-solidus cracking in welds (and castings). Br. Welding Journal, 7, 508-512.

${ }^{16}$ Shankar, V., Gill, T., Sundaresun, S. (2003). Solidification cracking in austenitic stainless steel welds. Sadhana, 28, 359-382., http://www.ias.ac.in/sadhana/Pdf2003JunAug/Pe1119.pdf.

${ }_{17}$ Borland, J. (1960). Generalized theory of super-solidus cracking in welds (and castings). Br. Welding Journal,7, 508-512.

${ }^{18}$ Cross, C.E. (2005) On the Origin of Weld Solidification, Hot Cracking Phenomena in Welds. (pp. 3-18). Berlin: Springer.

${ }^{19}$ Ramirez, A., Lippold, J. (2003). Ductility Dip Cracking of Ni-base Filler Metals—Insight into the Mechanism. Welding and Joining Metallurgy Group. http://files.aws.org/conferences/abstracts/2003/15c.pdf.

${ }^{20}$ Collins, M., Ramirez, A., Lippold, J. (2003). An Investigation of Ductility Dip Cracking in Nickel-Based Weld Metals - Part II. Welding Journal, 12, 348-354. http://files.aws.org/wj/supplement/12-2003-COLLINS-s.pdf. ${ }^{21}$ Collins, M.G. (2002) An investigation of ductility dip cracking in nickel-base filler materials, M.S. Thesis, The Ohio State University.

22 Young, G., Capobianco, T., Penik, M., Morris, B., Mcgee, J. (2008). The Mechanism of Ductility Dip Cracking in Nickel-Chromium Alloys. Welding Journal, 87, 31-42.

${ }^{23}$ Metzler, D. (2008). A Gleeble-based Method for Ranking the Strain-Age Cracking Susceptibility of Ni-Based Superalloys. Welding Journal, 87, 249-256.

${ }^{24}$ Prager, M., Shira, C.S. (1968). Welding of precipitation hardenable nickel-base alloys, WRC Bulletin No. 128. 
${ }^{25}$ Campbell, R, Walsh, D. (2000) Weldability testing, ASM International.

${ }^{26}$ Lundin, C., Menon, R., Lee, C., Osorio, V. (1986). New concepts in varestraint testing for hot cracking. Welding Research: The State of the Art, JDC University Research Symposium Proceedings, ASM, 33-42.

${ }^{27}$ Shankar, V., Gill, T., Sundaresun, S. (2003). Solidification cracking in austenitic stainless steel welds. Sadhana, 28, 359-382., http://www.ias.ac.in/sadhana/Pdf2003JunAug/Pe1119.pdf.

${ }^{28}$ Davis, J. (2000). Nickel, Cobalt, and Their Alloys. (pp. 38-40) Materials Park: ASM International.

${ }^{29}$ Gao, M., Wei, R. (1995). Grain boundary $\gamma^{\prime \prime}$ precipitation and niobium segregation in inconel 718. Scripta Metallurgica et Materialia, 32(7), 987-990.

${ }^{30}$ Savage, Lundin. (1965). The Varestraint Test. Welding Journal Research Supplement,

${ }^{31}$ Shankar, V., Gill, T., Mannan, S., Sundaresan, S. (2003). Solidification cracking in austenitic stainless steel welds. Sadhana, 28(3 \& 4), 359-382.

${ }^{32}$ Kammer, Masuhachi, Monroe. (1964) Cracking in high-strength steel weldments - A Critical Review. DMIC Report 197.

${ }^{33}$ Campbell, R, Walsh, D. (2000) Weld Pool Classification, ASM International

${ }^{34}$ Bonesteel, T. (2004) Gleeble Systems: Physical Simulation Technology. Sunchon National University . Material Physics Laboratory, Korea.

35 Davis, J. (1997). Heat-Resistant Materials (pp. 207-220). Materials Park: ASM International.

${ }^{36}$ Chhatre, R. (2006) Weldability and Post-Weld Heat Treatment of a Novel Ni-Based Alloy. Thesis. California Polytechnic State University, 206. San Luis Obispo: Cal Poly State University.

${ }^{37}$ Baeslack, W., Lin, W., \& Lippold, J. (1993). A methodology for quantifying HAZ liquation cracking susceptibility using the gleeble hot-ductility test. Welding Journal, 72(4), 135-153.

${ }^{38}$ Nippes, E.F., Savage, W.F., and Grotke, G. (1957) Welding Research Concin Bulletin No. 33.

${ }^{39}$ Demyantsevich, V.P. (1967) Welding Production 14(3), 1-6.

40 Owczaski, W., Duvall, D., \& Grotke, G. (1966). Model for Heat-Affected Zone Cracking in Ni-Base Superalloys. Welding Journal, 45(4), 145s-155s.

41 Owczaski, W., Duvall, D. (1967). Further Heat Affected Zone Solidification Cracking in Heat Resistant Nickel Alloys. Welding Journal 46(9), 423s-432s.

42 Williams, C. (1963). Steel Strength and Ductility Response to Arc-Welding Thermal Cycles. Welding Journal 42(1) $1 \mathrm{~s}-8 \mathrm{~s}$.

${ }^{43}$ Lin, W., Baeslack, W.A., Lippold, J.C. (1989) Recent trends in welding science and technology. TWR ASM International, 609-614. 